\title{
Legal Status and Rights of the Pet (companion) Animals and Ensuring Their Harmonious Coexistence with Citizens According to Legislation of Georgia
}

\author{
Kakhaber loseliani \\ Iv. Javakhishvili Tbilisi State University, Master of Law, German Society for International Cooperation \\ (GIZ), Lawyer - Member of the LEPL Georgian Bar Association
}

\section{ARTICLE INFO}

Article History:

Received 6.10.2021

Accepted 26.10.2021

Published 20.12.2021

\section{Keywords:}

Pet, Right, Humane

\section{ABSTRACT}

The goal of the present article is to give the reader an insight in the problems of regulating pet issues in Georgia, as well as ongoing trends and up-to-date views in the European countries, to identify the causes of problems of legal regulation and management in the given field and to give an impetus to those interested in the topic and problems to find ways to address the problem.

The source of the article was the effective legislation of Georgia, which was duly studied, including the normative acts adopted by the central authority and municipal bodies, as wellas the national legislations of the European countries, international legal documents and the managerial practice of the branch in Georgia.

Following the study of the problem considered in the article, it was found that Georgia lacks a single legal framework to systematically and thoroughly regulate pet issues. Neither does the country have a legislative act that would define the status of pets. Consequently, there is no quality and comprehensive legal document at the municipal level derived from the nationwide legislative act. There have been attempts at the levels of both, the central government and concrete municipalities, to address pet issues. However, such attempts are fragmental and non-systemic and fail to cover complex measures. As a result, it is impossible to obtain a desirable outcome in respect of safety of people and animals and protection of animal rights. 


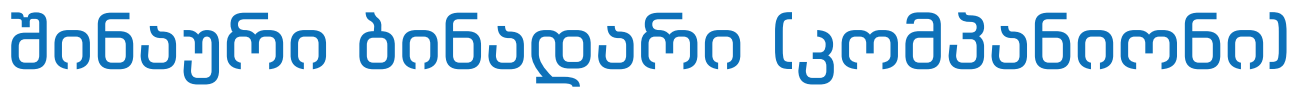

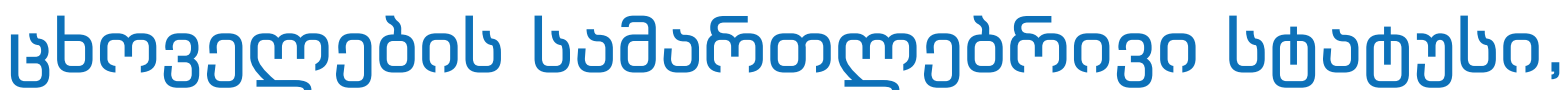

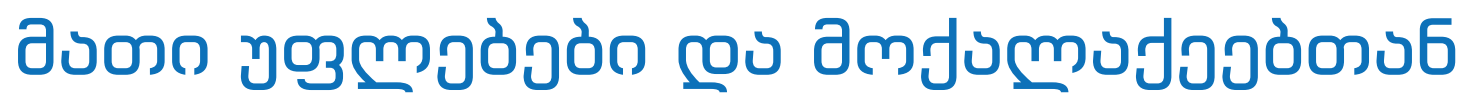

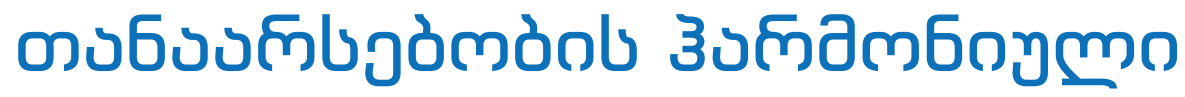

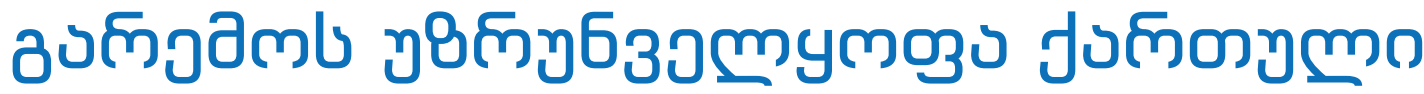

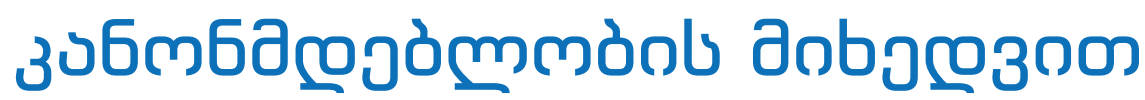

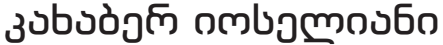

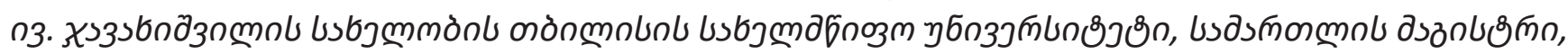

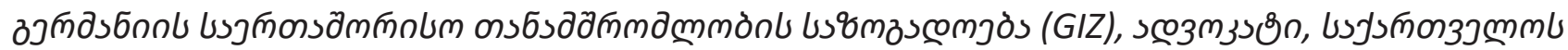

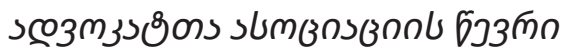

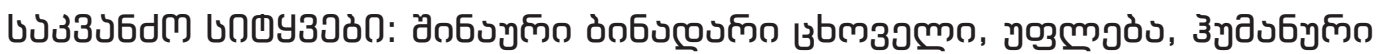

\section{วอเป3งmo}

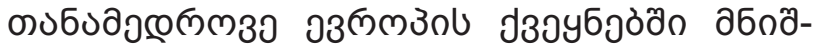

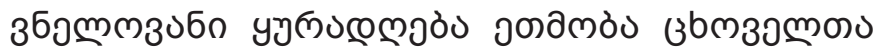

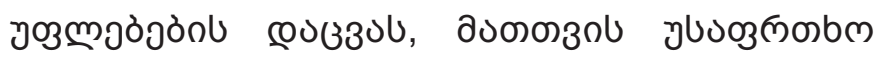

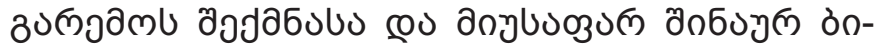

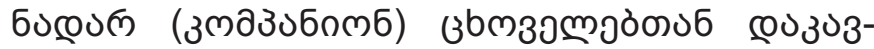

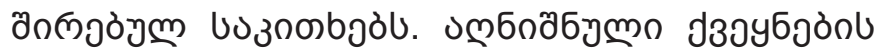

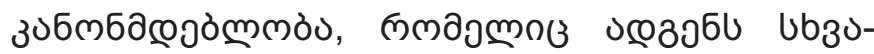

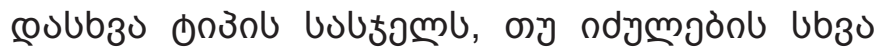

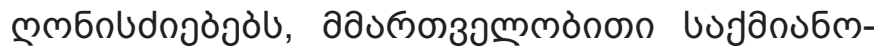

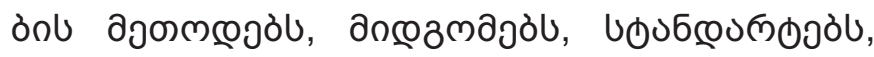

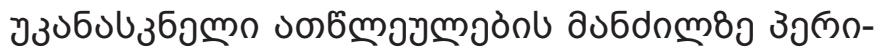

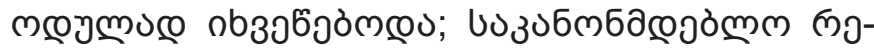

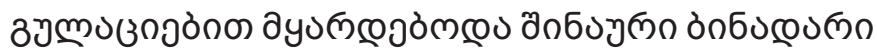

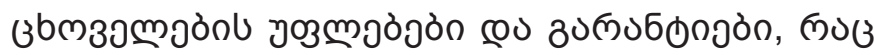

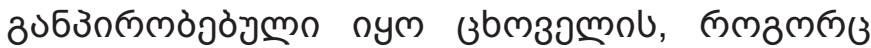

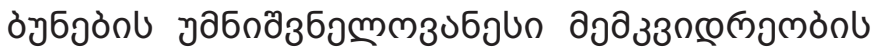

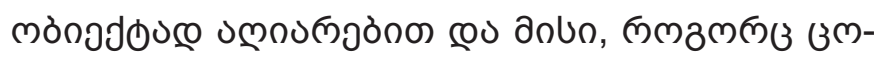

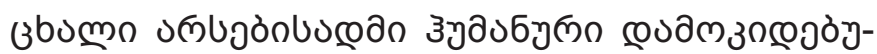

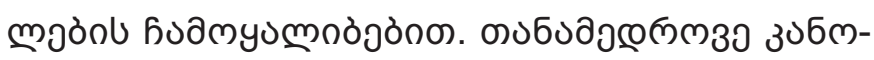

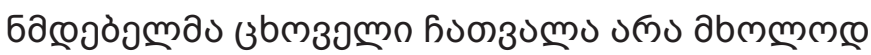

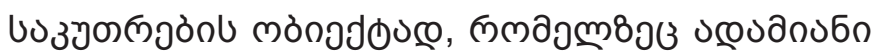

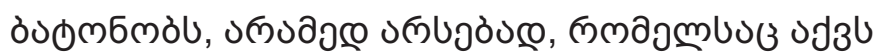

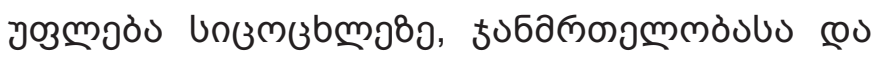

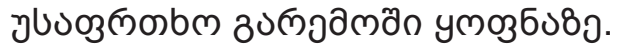

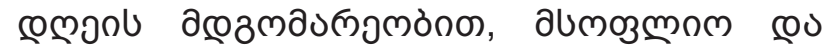

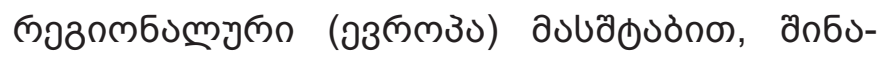

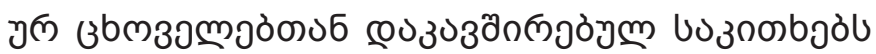

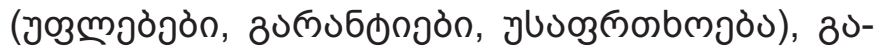

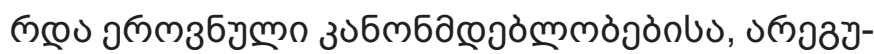

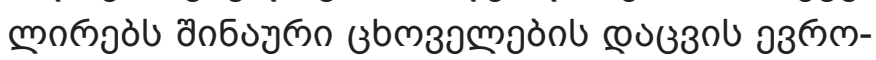

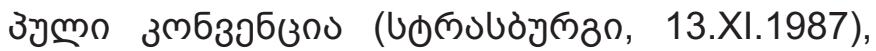

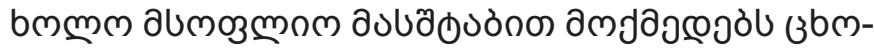

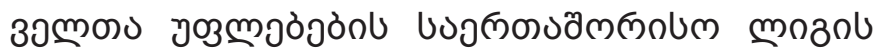

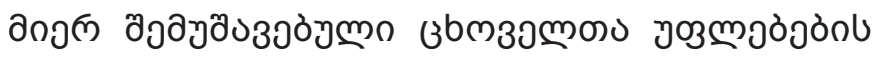

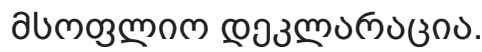

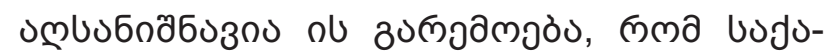

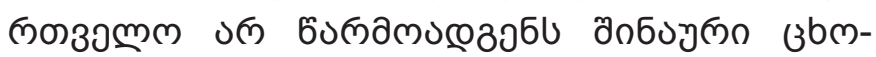

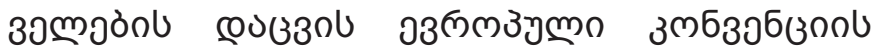




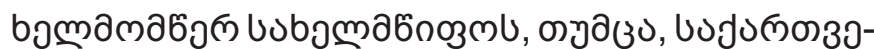

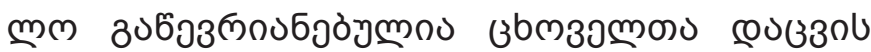

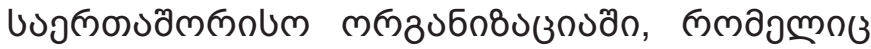

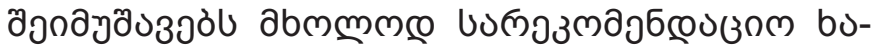

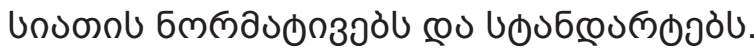

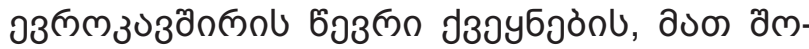

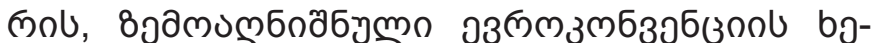

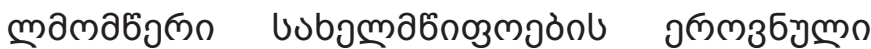

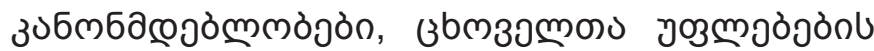

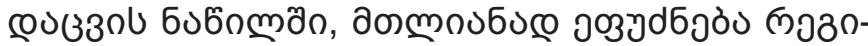

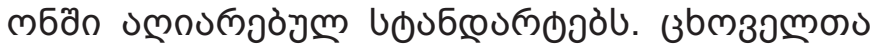

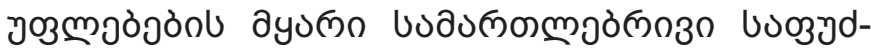

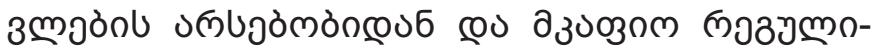

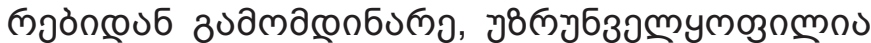

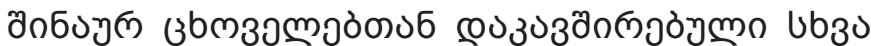

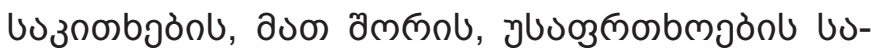

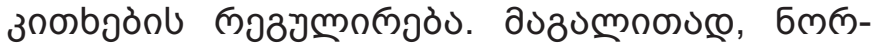

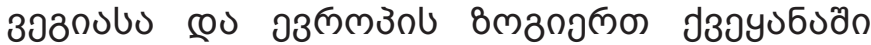

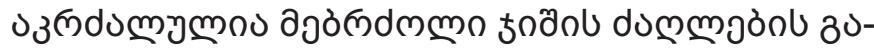

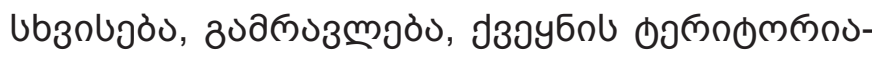

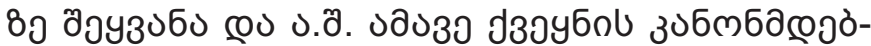

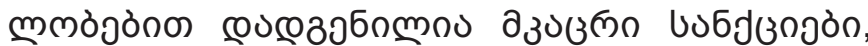

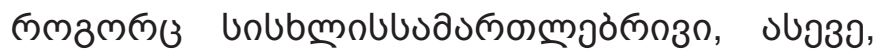

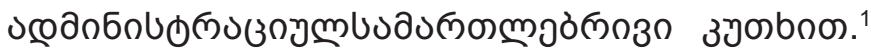

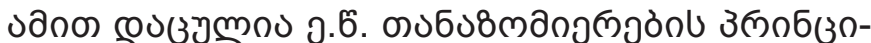

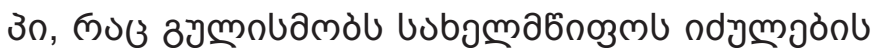

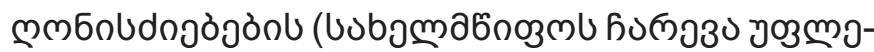

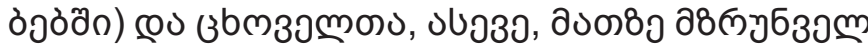

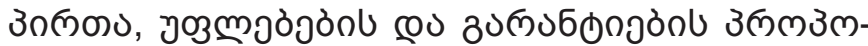

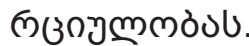

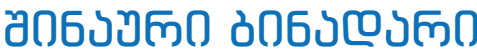

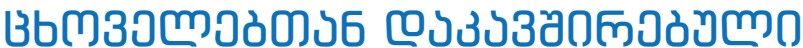

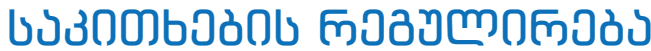

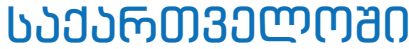

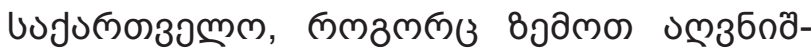

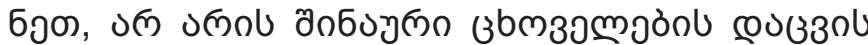

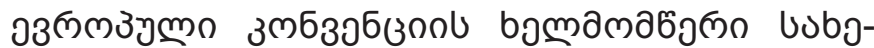

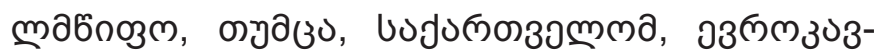

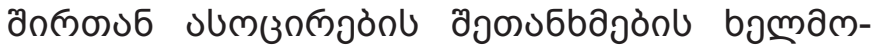

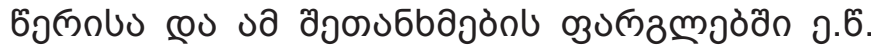

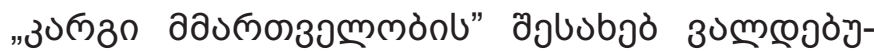

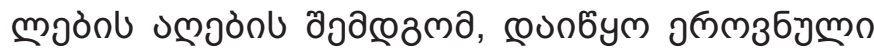

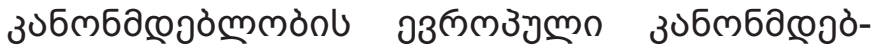

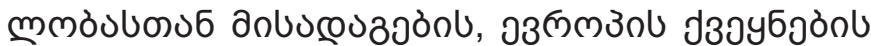

1 Regulations on dogs. https://lovdata.no/dokument/SF/ forskrift/2004-08-20-1204

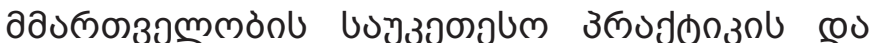
couco

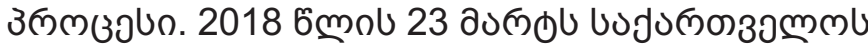

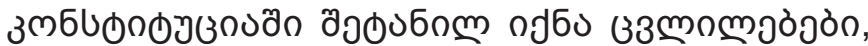

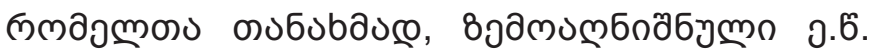

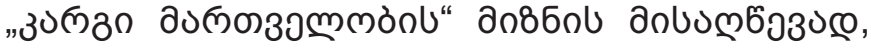

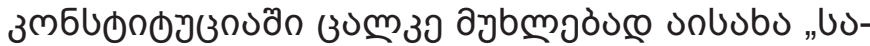

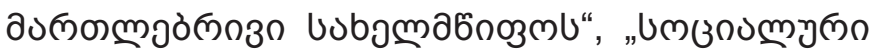

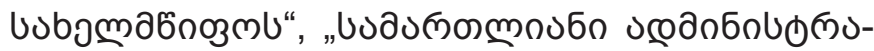

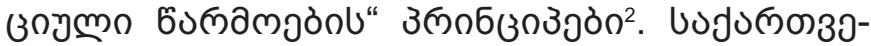

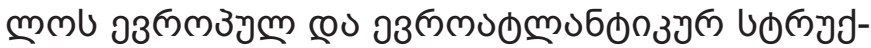

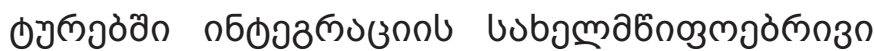

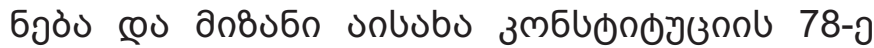

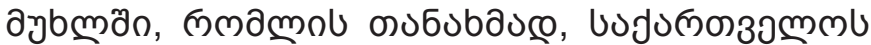

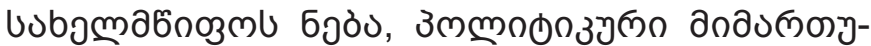

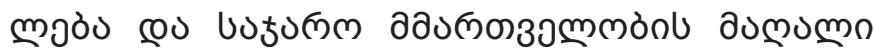

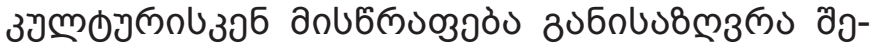

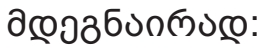

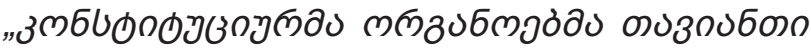

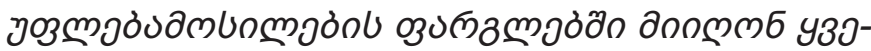

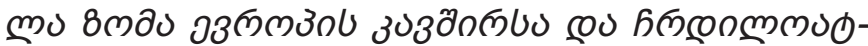

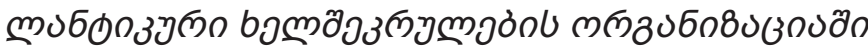

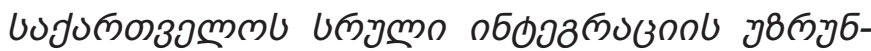

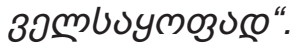

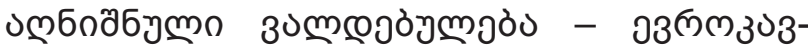

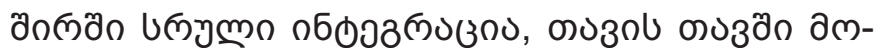

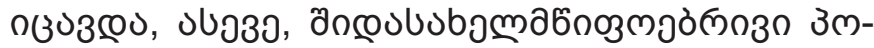

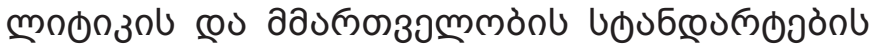

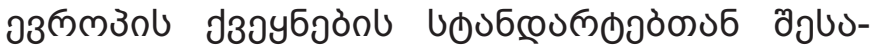

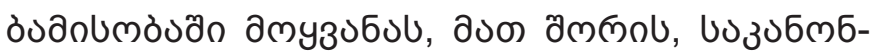

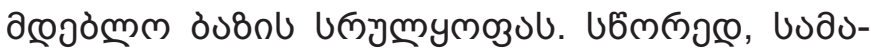

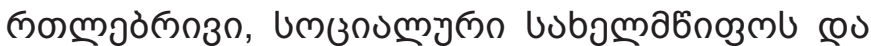

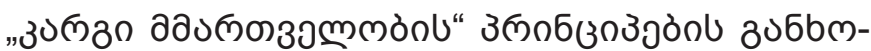

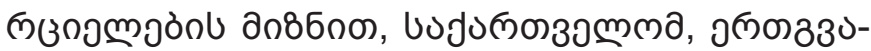

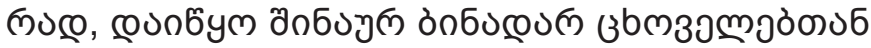

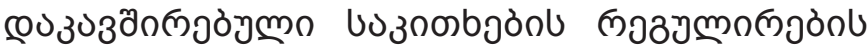

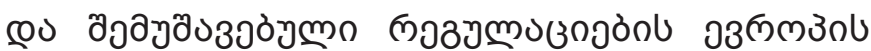

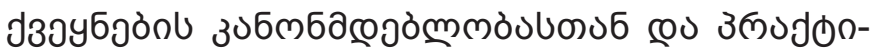

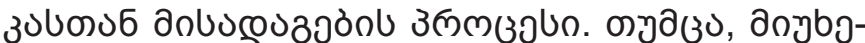

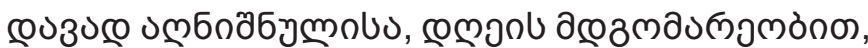

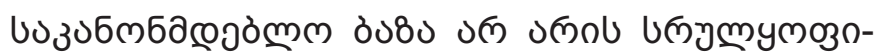

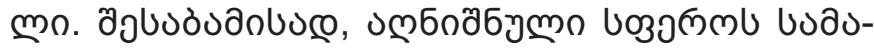

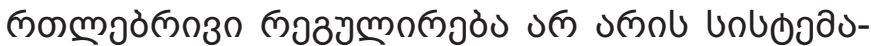

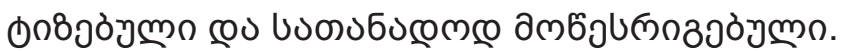

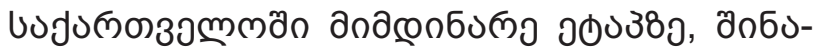

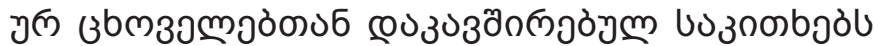

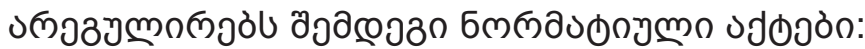

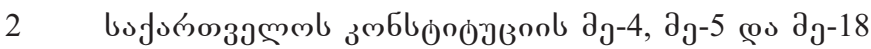
дybmà̀o. 


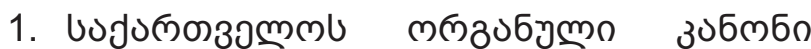

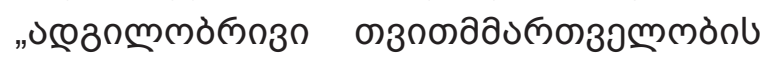

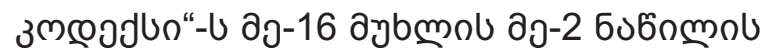
„ॅ“ Ј30зубगळ

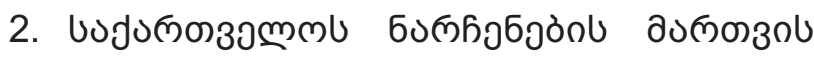
उलณоJu

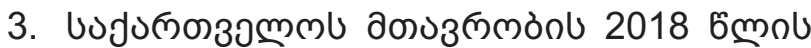
28 nзбоunl \#345 couূo

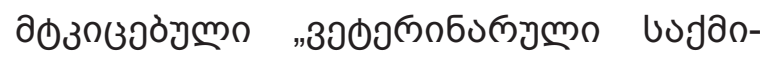

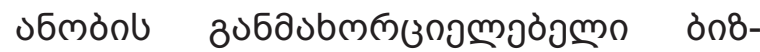

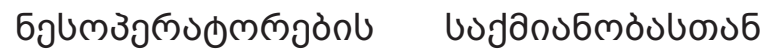

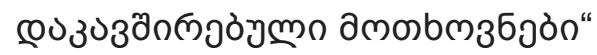

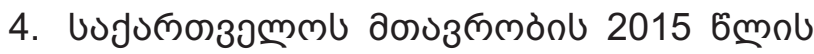
14 nзmolnu \#348 couso

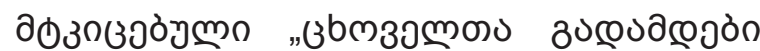

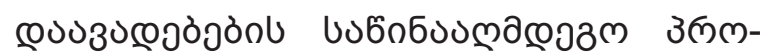

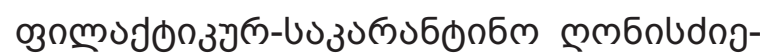

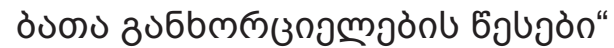

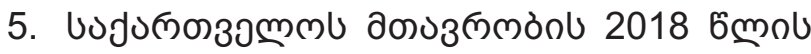

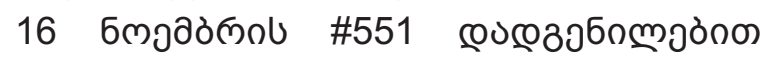

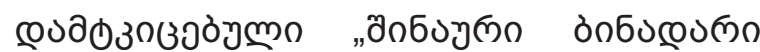

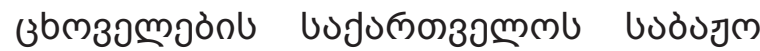

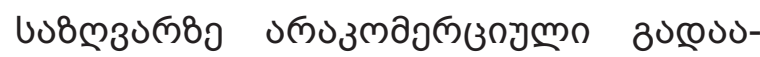
cozomjòn 6oun"

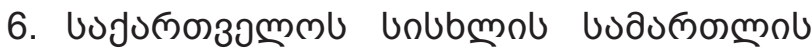

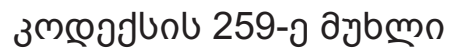

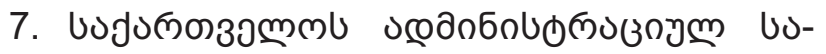

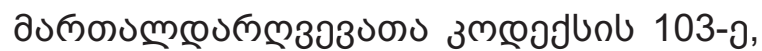

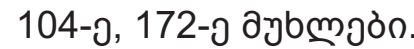

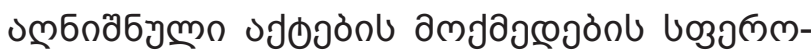

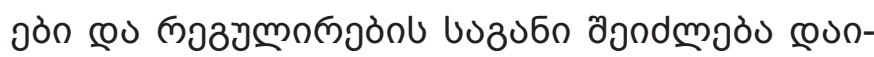

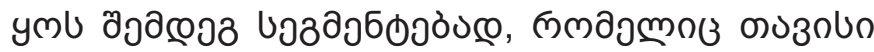

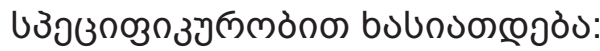

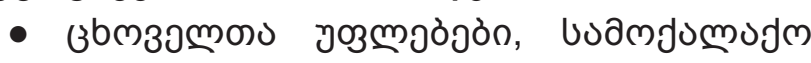

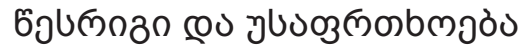

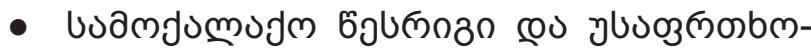
jò;

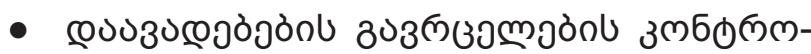
mo.

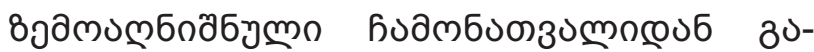

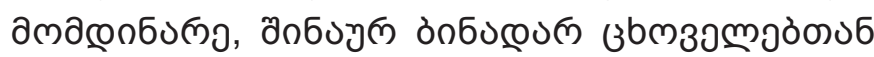

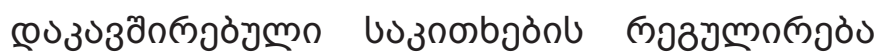

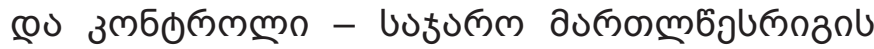

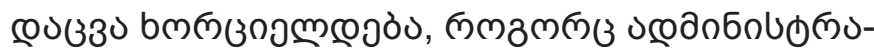

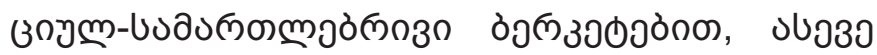

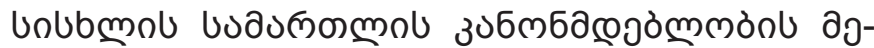

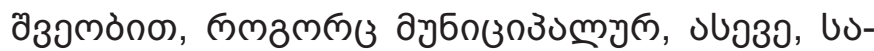

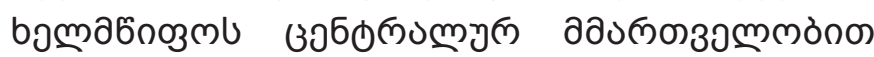
com6080.

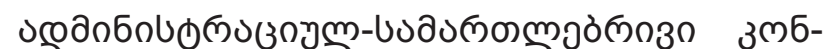

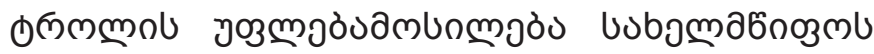

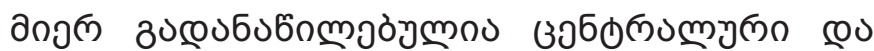

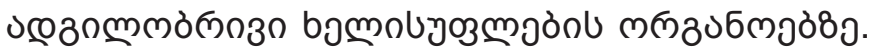

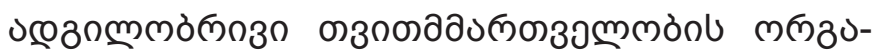

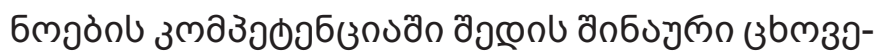

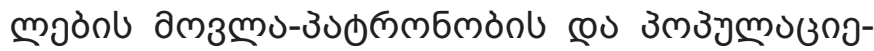

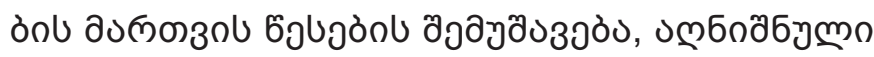

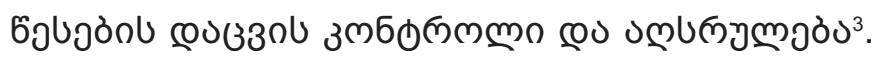

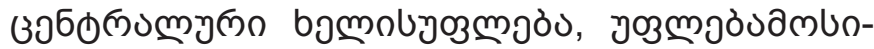

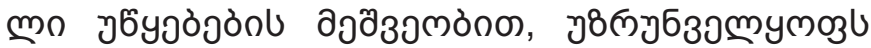

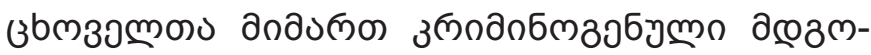

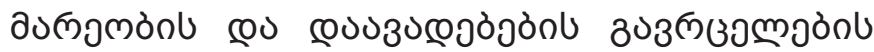

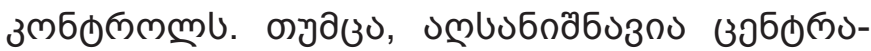

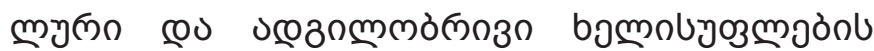

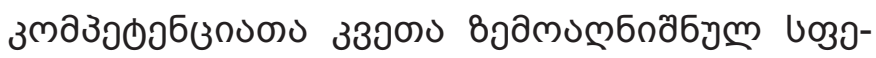

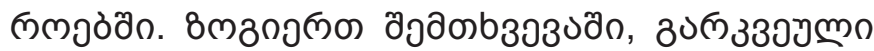

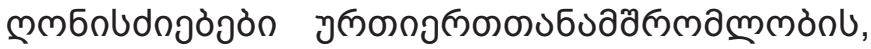

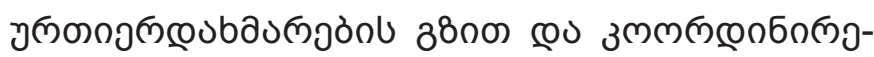

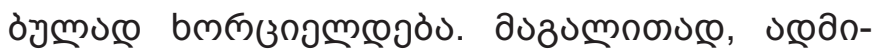

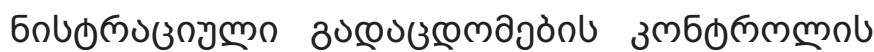

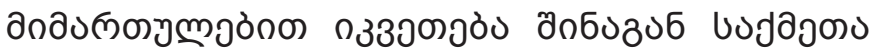

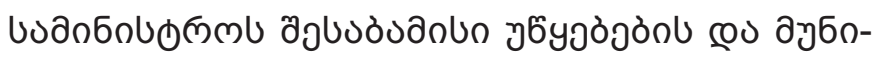

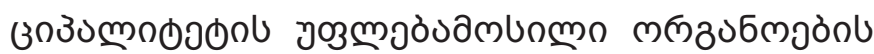

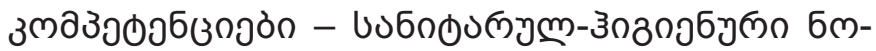

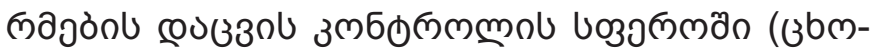

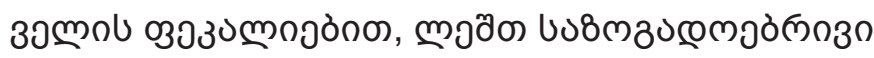

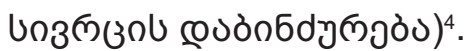

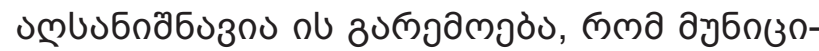

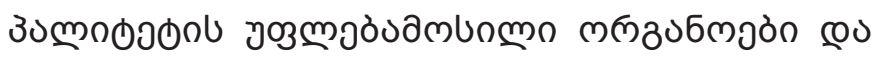

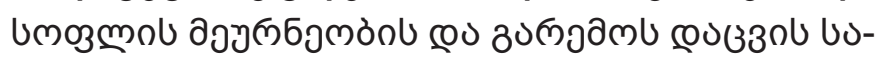

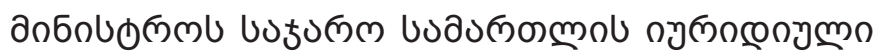

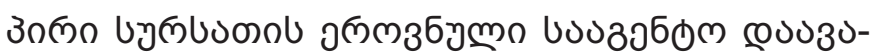

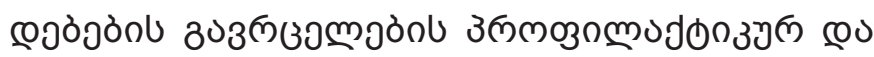

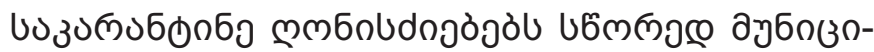

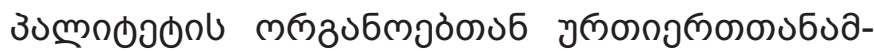

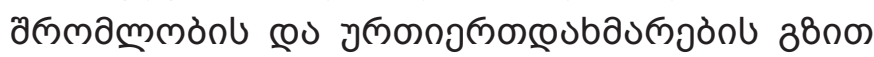

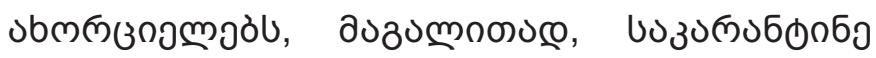

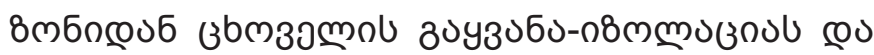

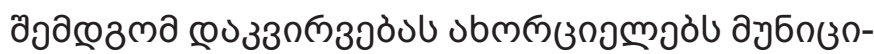

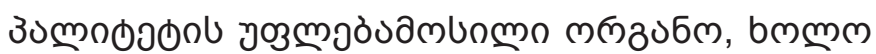

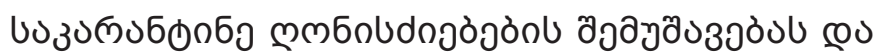

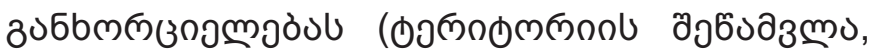

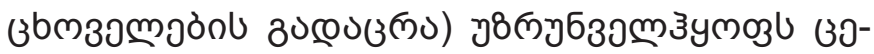

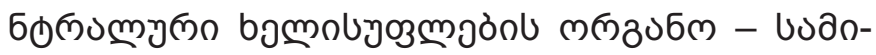

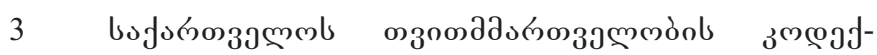

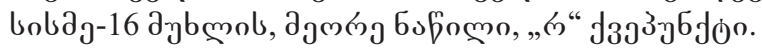

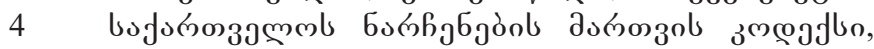

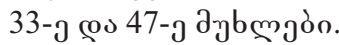




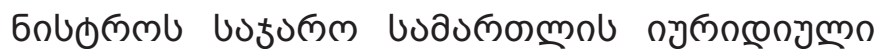

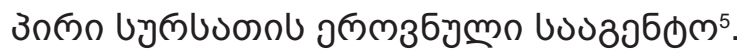

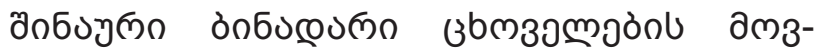

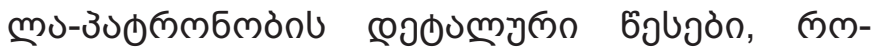

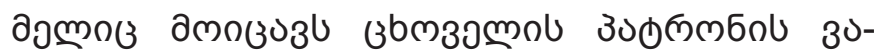

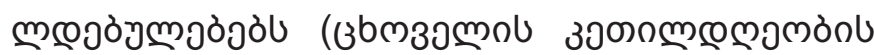

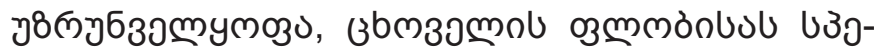

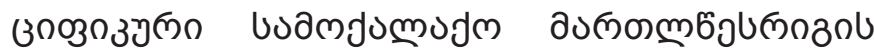

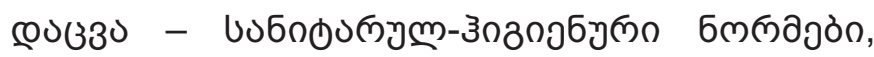

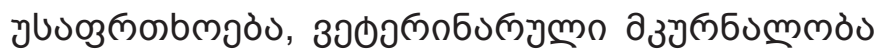

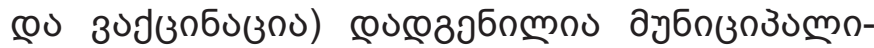

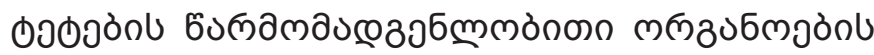

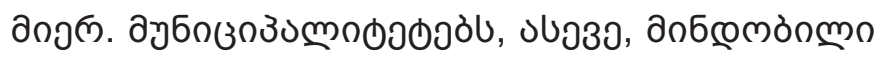

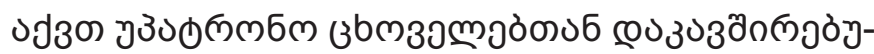

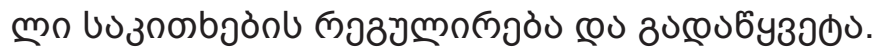

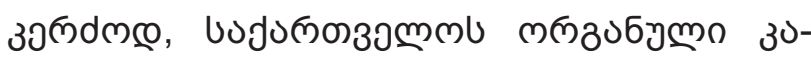

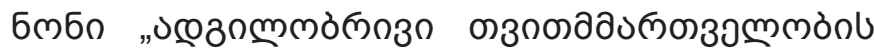

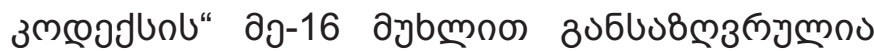

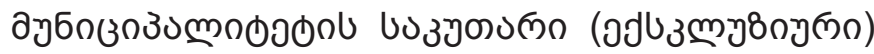

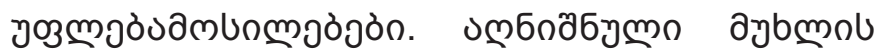

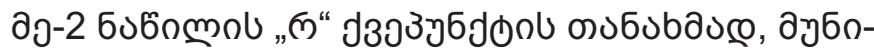

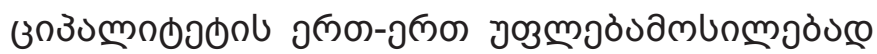

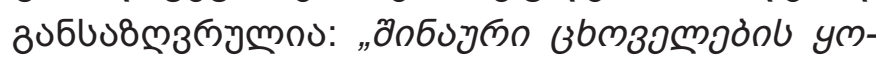

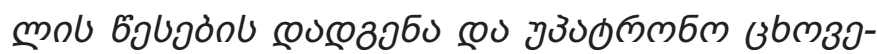

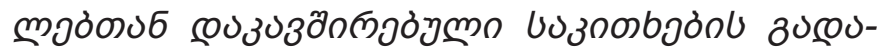
6y3000".

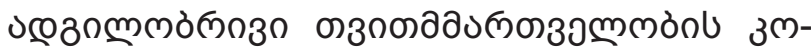

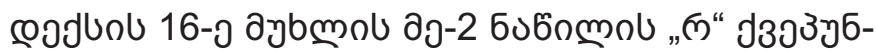

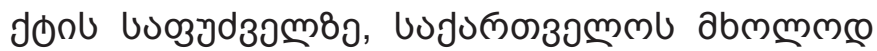

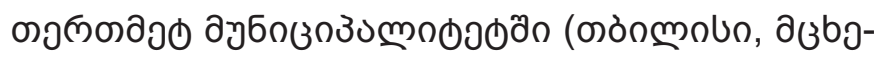

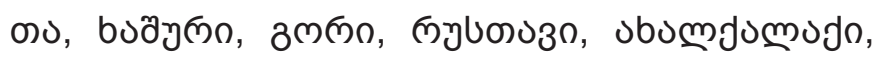

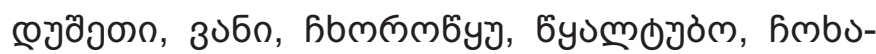

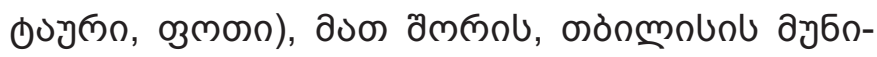

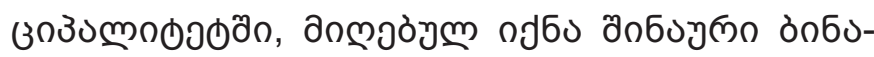

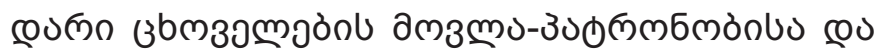

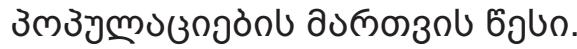

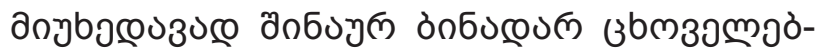

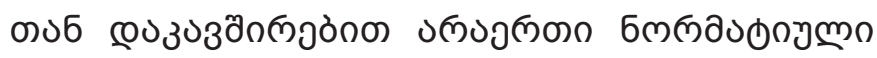

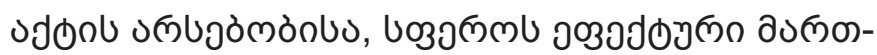

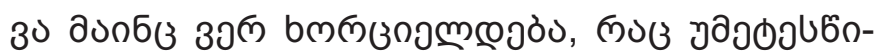

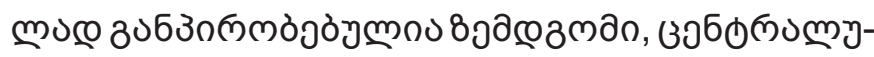

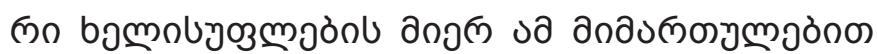

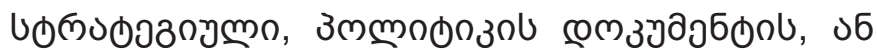

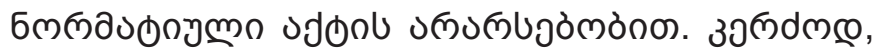

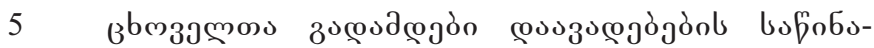

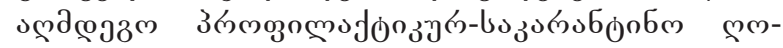

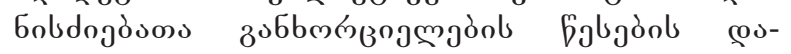

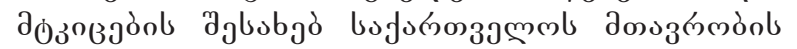

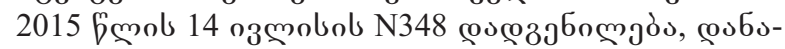
๓ок N5, ว

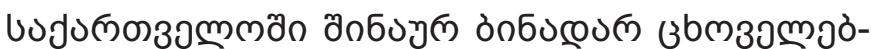

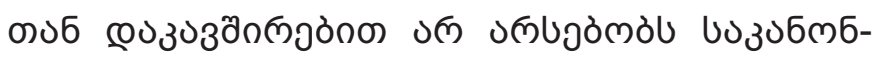

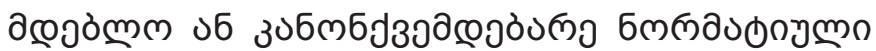

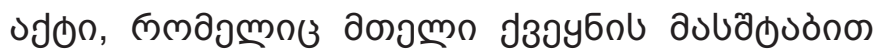

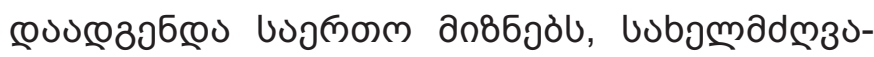

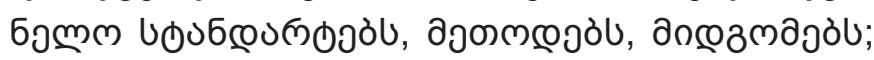

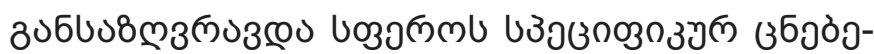

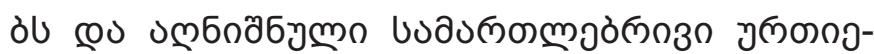

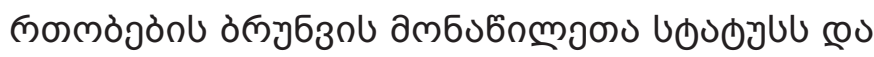

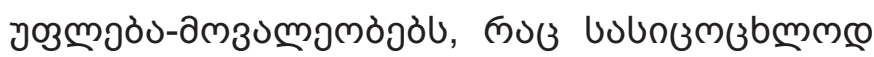

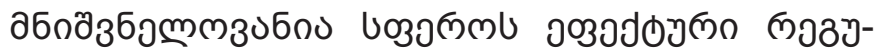

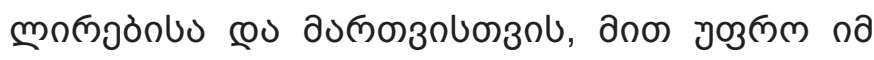

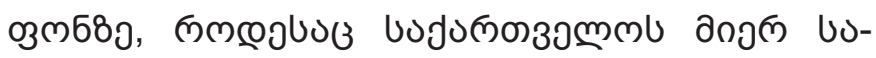

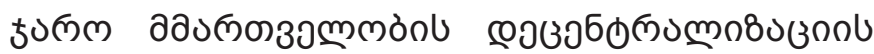

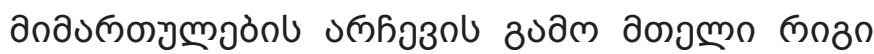

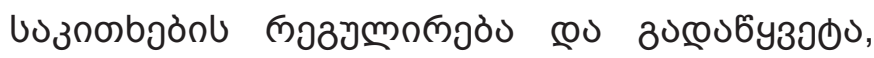

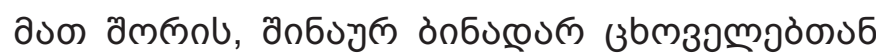

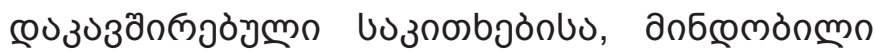

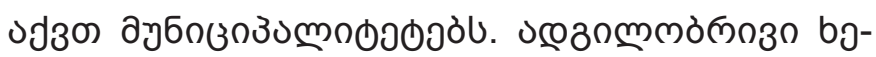

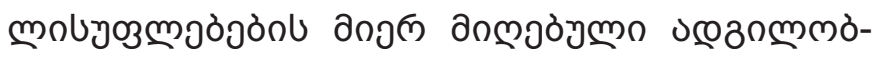

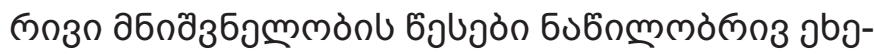

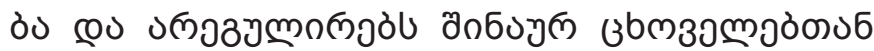

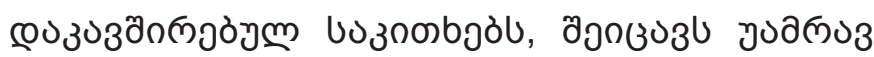

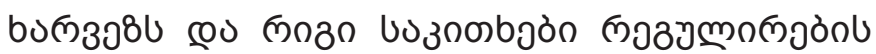

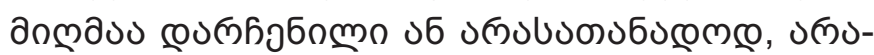

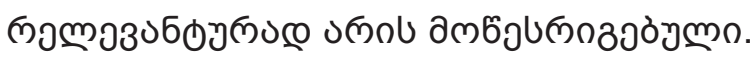

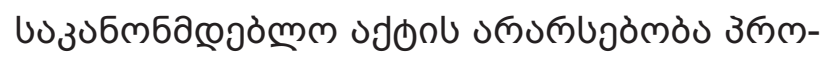

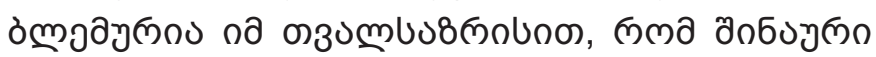

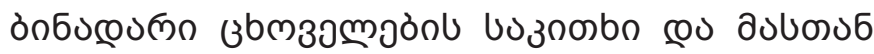

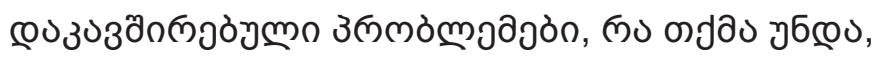

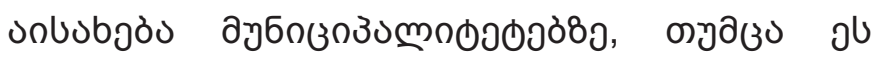
उलмd்

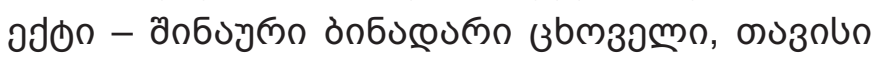

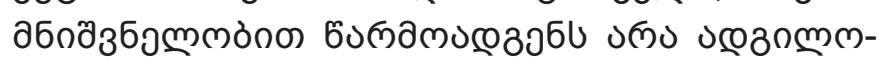

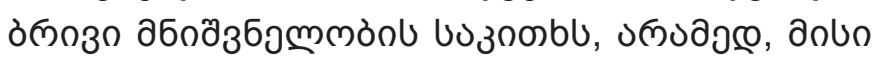

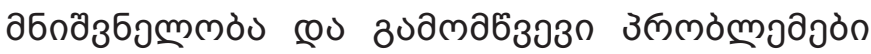

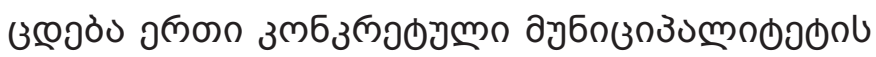

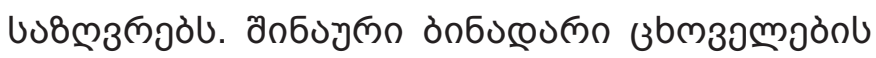

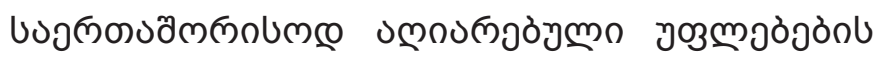

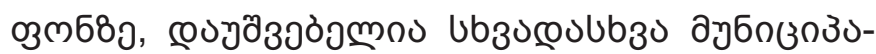

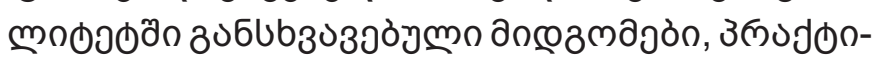

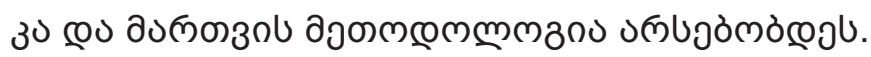

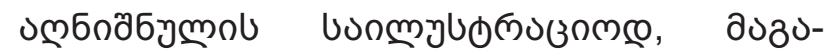

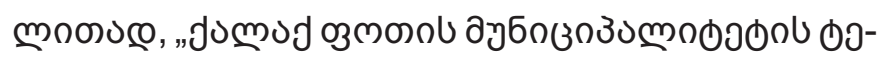

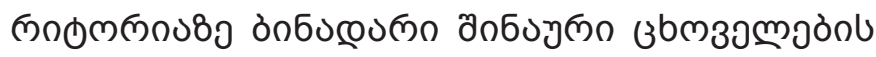

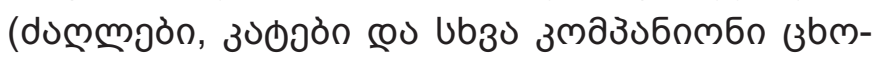

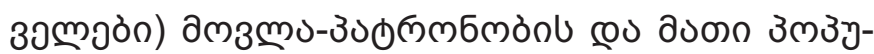

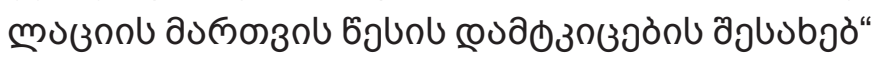

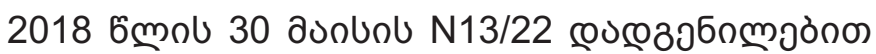




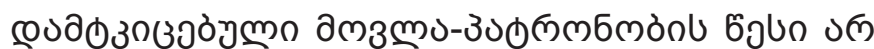

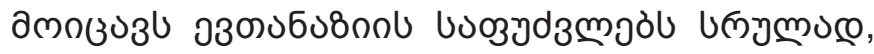

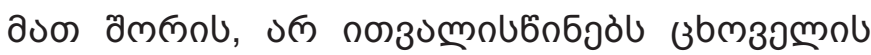

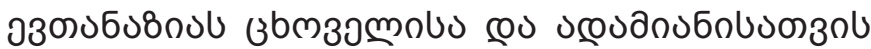

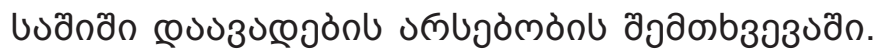

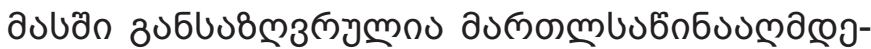

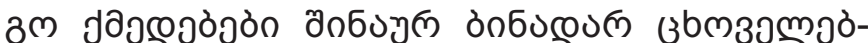

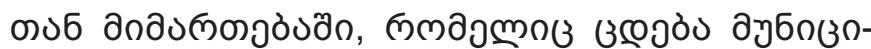

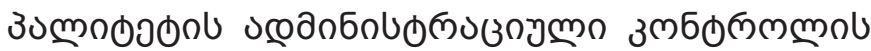

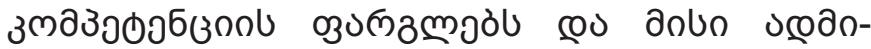

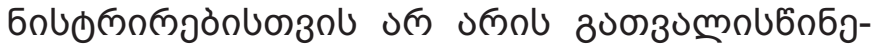

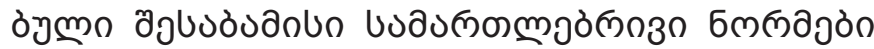

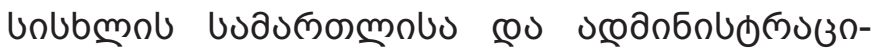

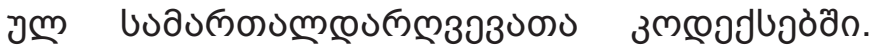

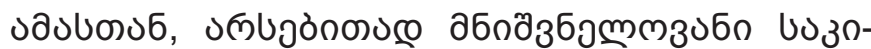

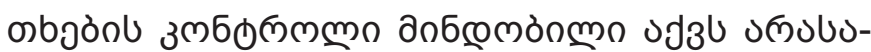

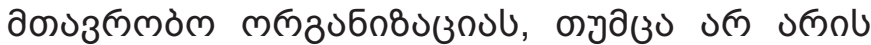

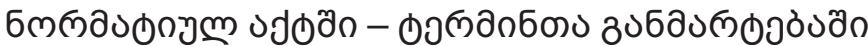

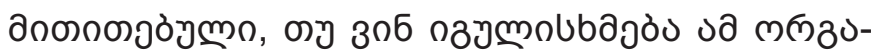

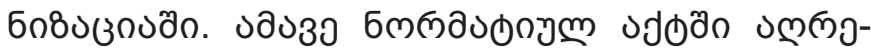

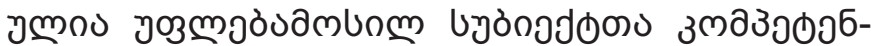

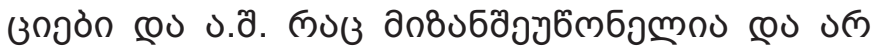

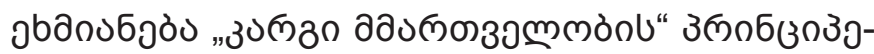

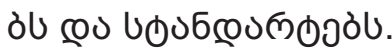

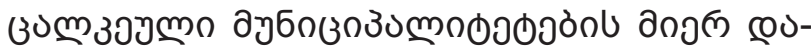

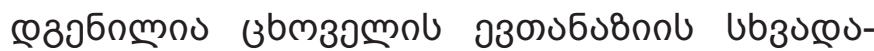

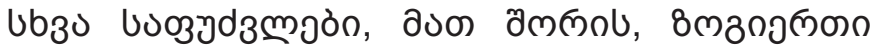

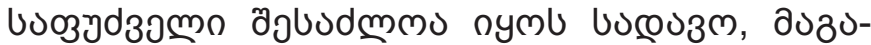

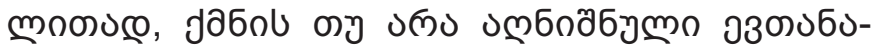

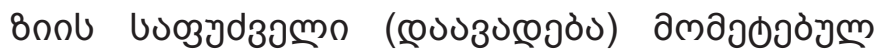

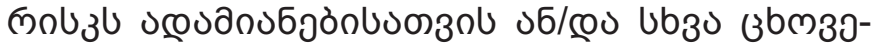

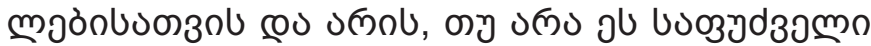

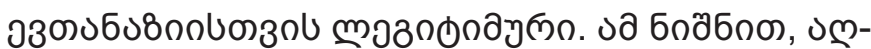

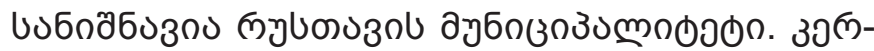

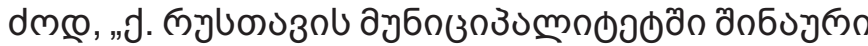

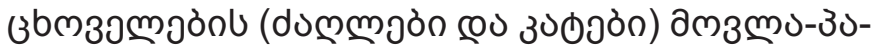

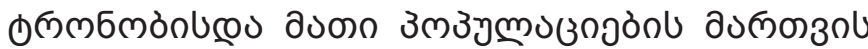

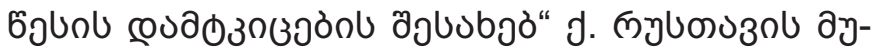

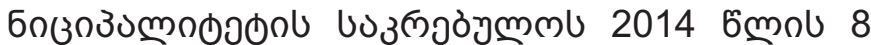

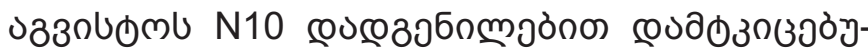

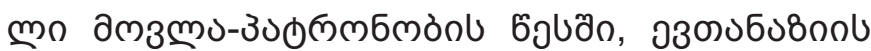

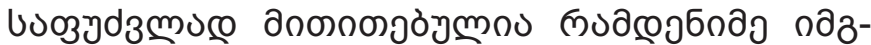

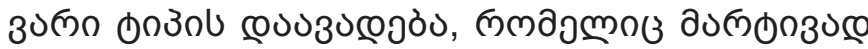
аงбзУलб

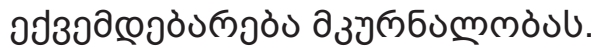

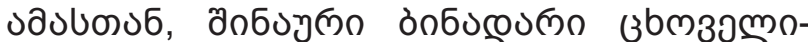

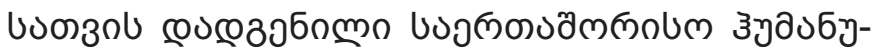

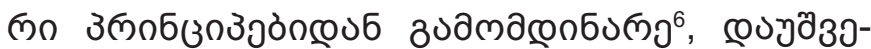

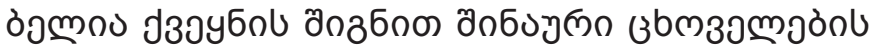

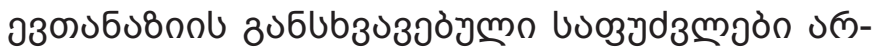
ujòmóngol.

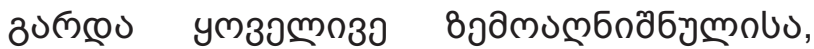

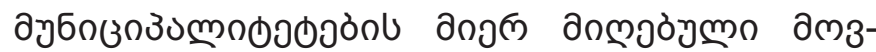

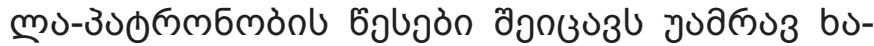

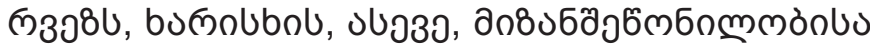

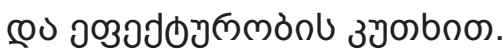

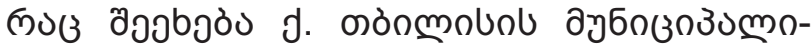

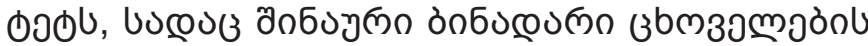

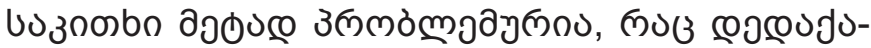

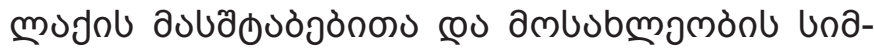

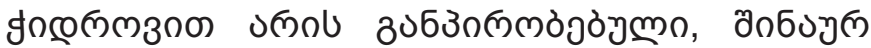

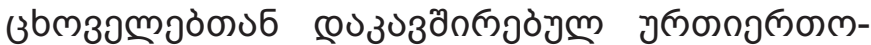

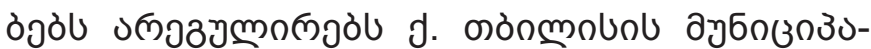

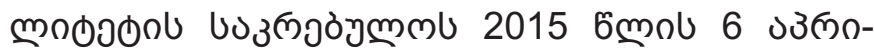

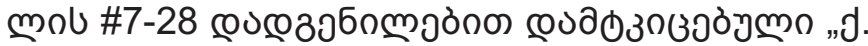

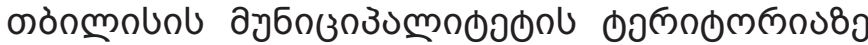

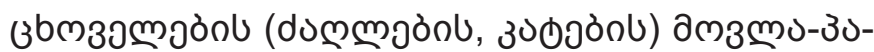

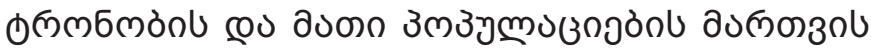

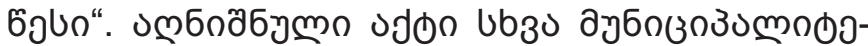

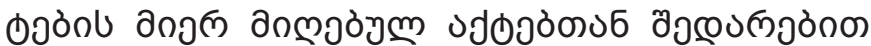

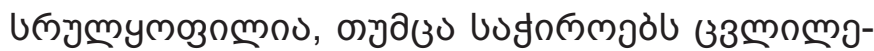

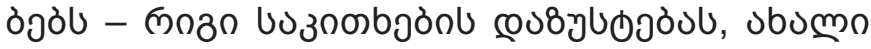

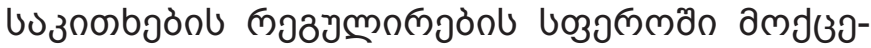

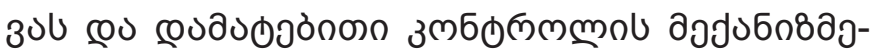

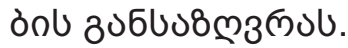

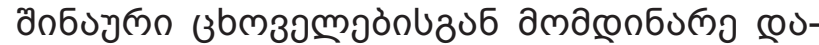

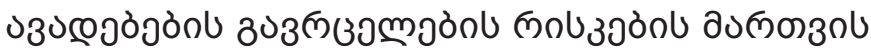

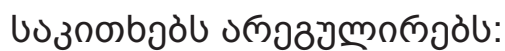

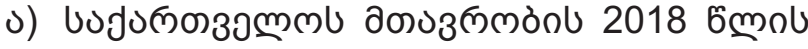

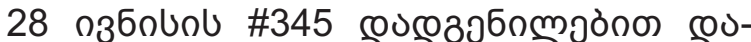

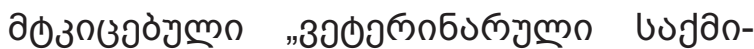

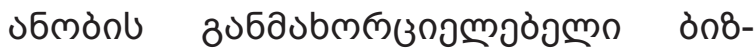

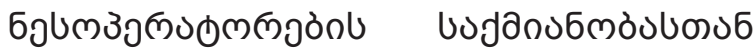

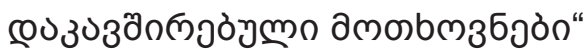

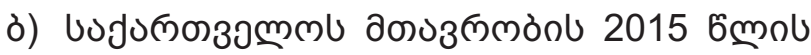
14 nзmolno \#348 couso

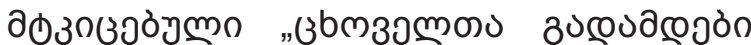

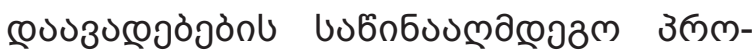

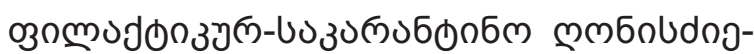

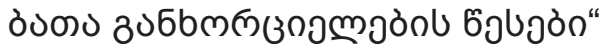

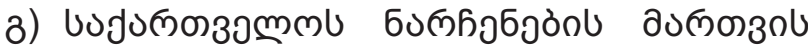

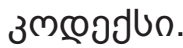

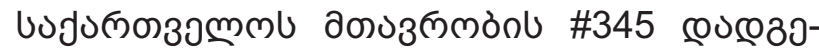

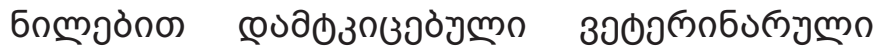

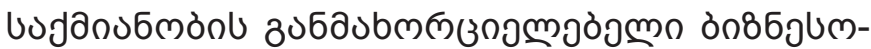

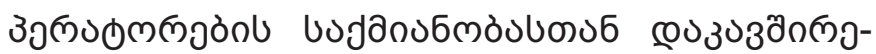

Universal Declaration of Animal Rights. 


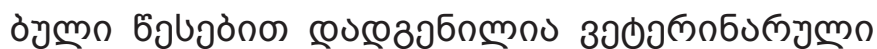

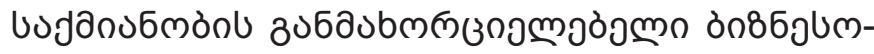

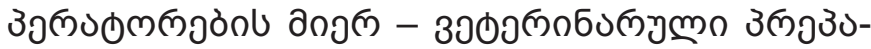

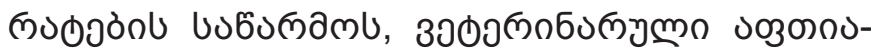

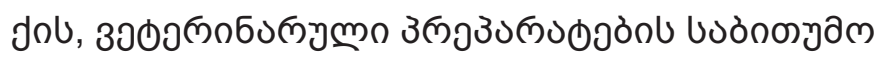

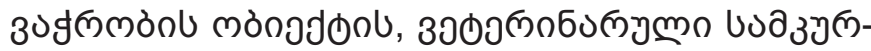

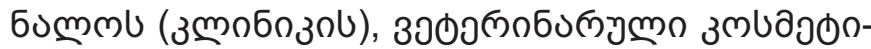

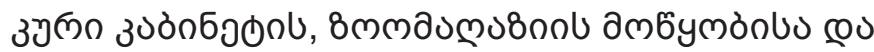

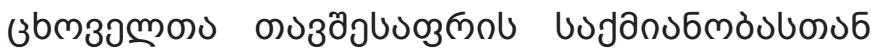

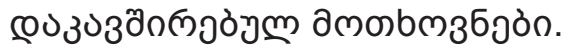

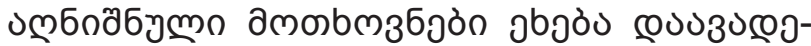

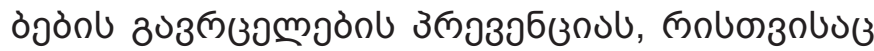

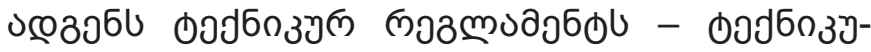

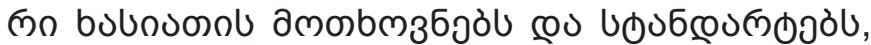

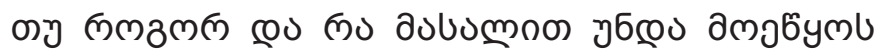

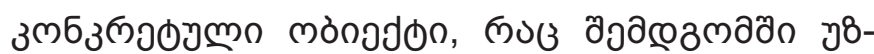

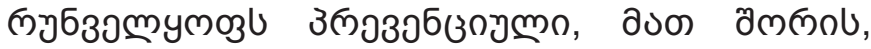

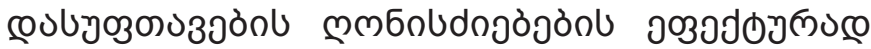

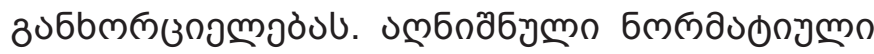

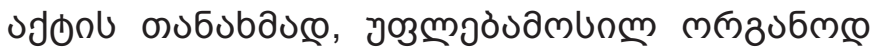

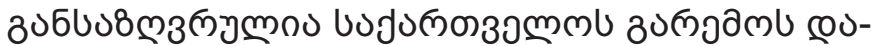

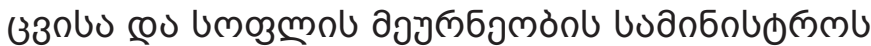

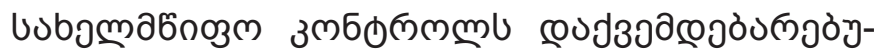

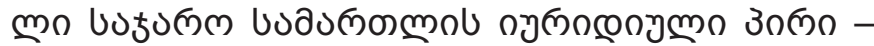

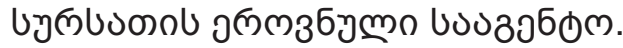

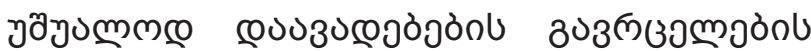

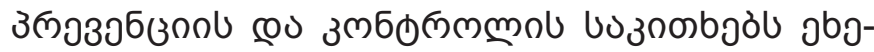

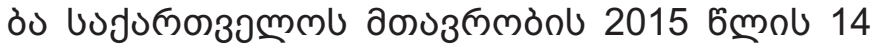

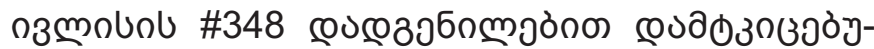

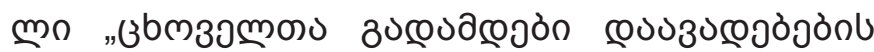

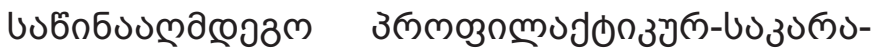

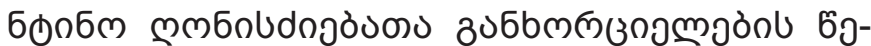

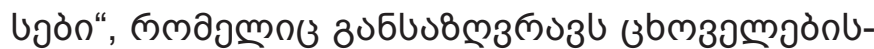

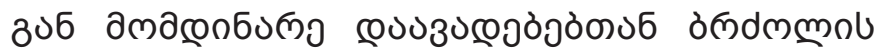

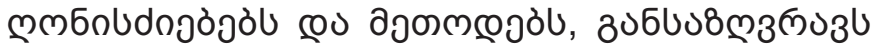

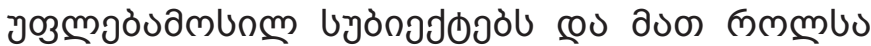

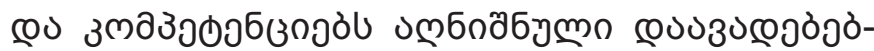

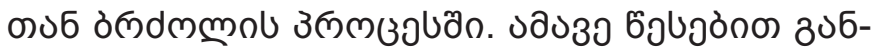

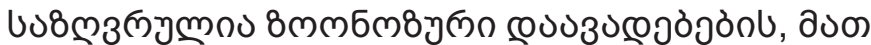

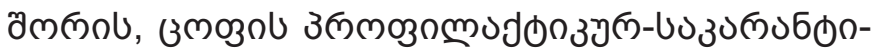

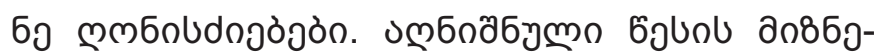

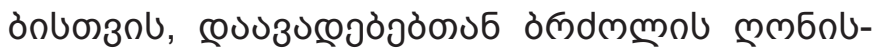

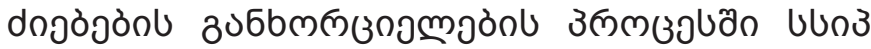

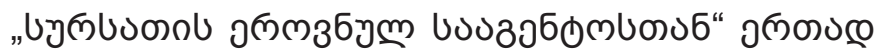

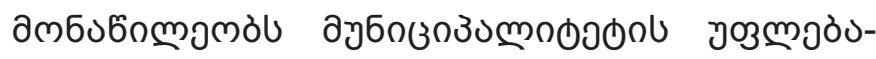

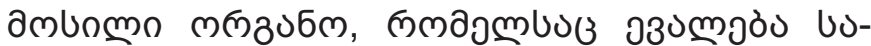

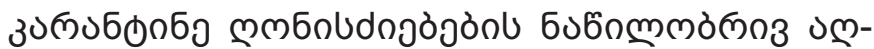

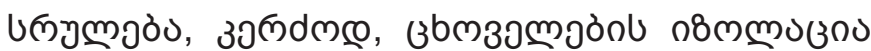

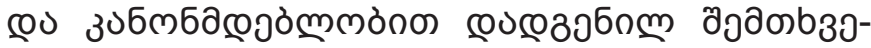

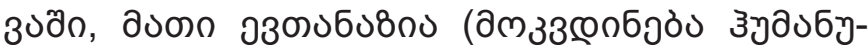

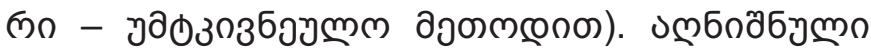

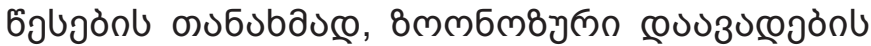

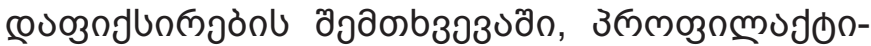

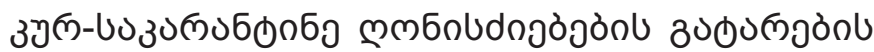

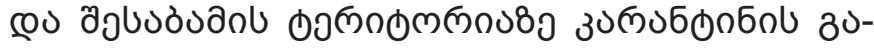

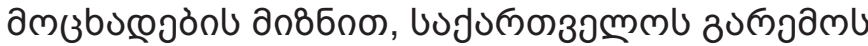

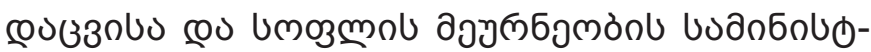

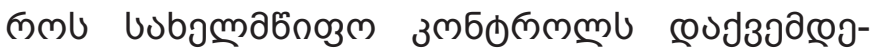

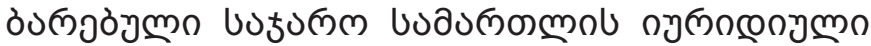

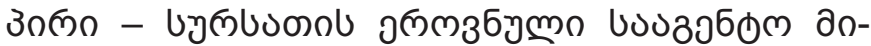

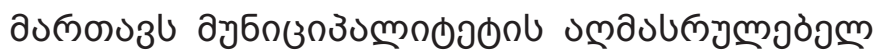

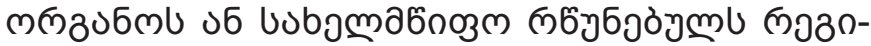

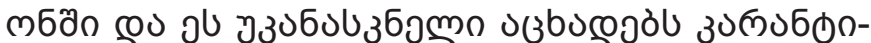

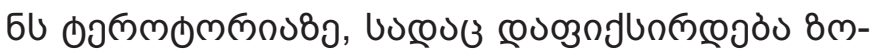

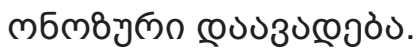

ง

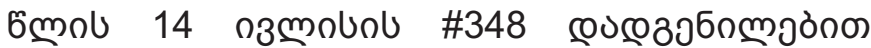

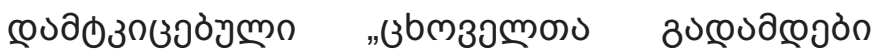

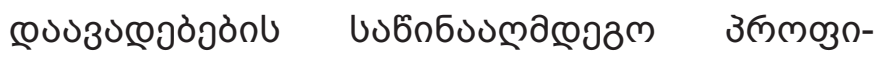

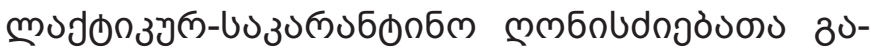

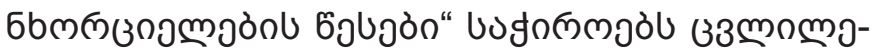

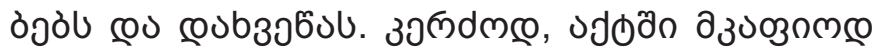

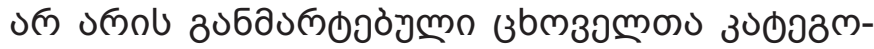

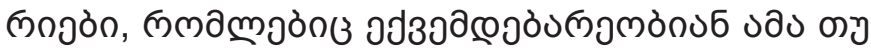

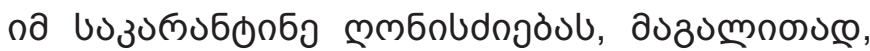

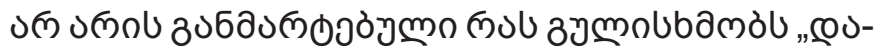

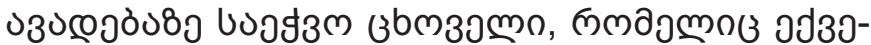

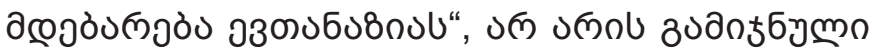

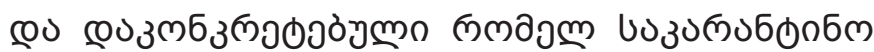

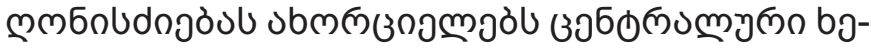

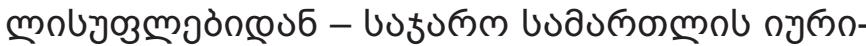

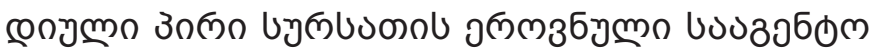

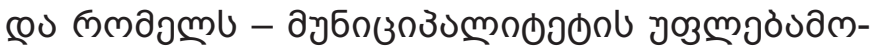

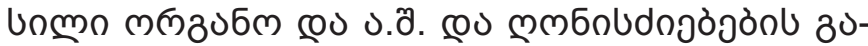

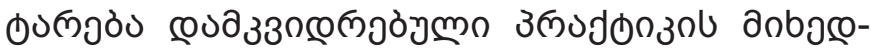

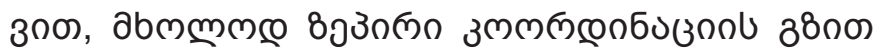

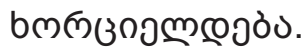

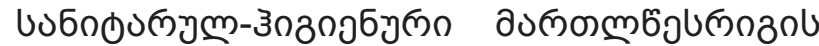

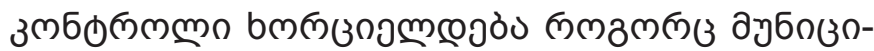

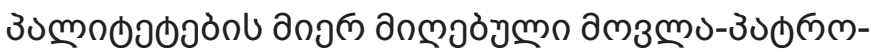

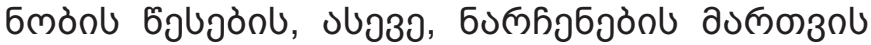

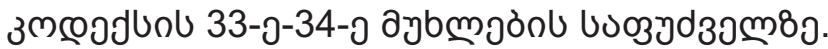

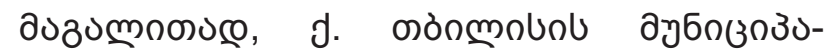

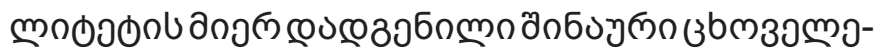

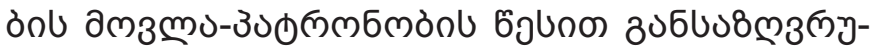

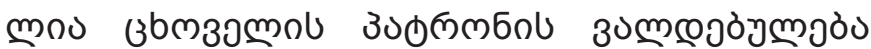

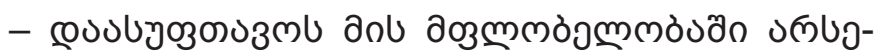

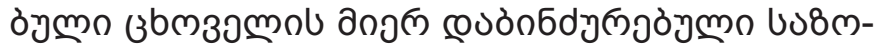




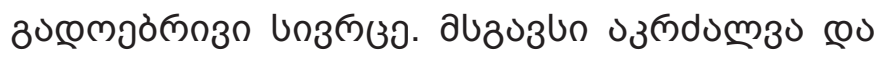

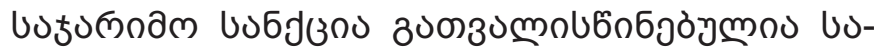

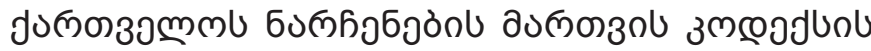

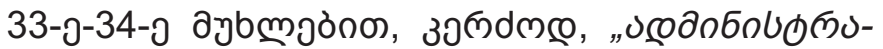

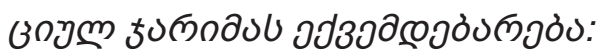

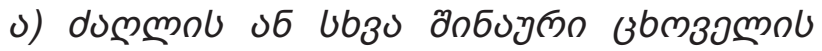

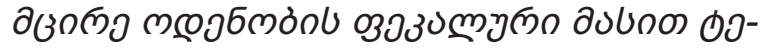

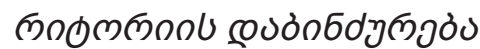

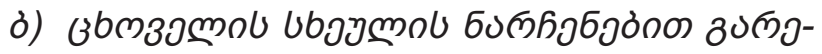

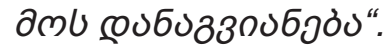

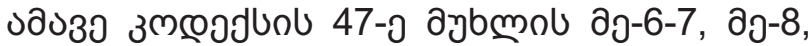

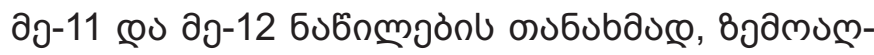

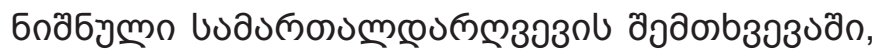

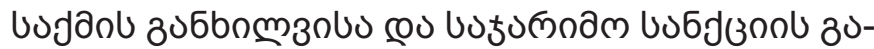

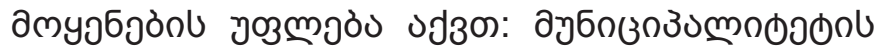

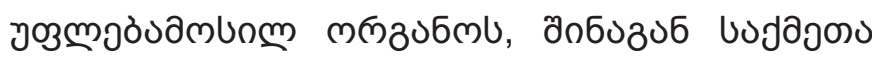

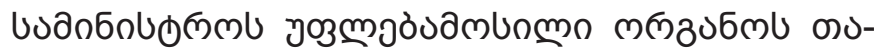

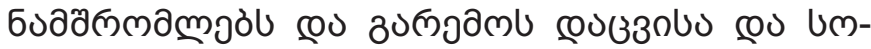

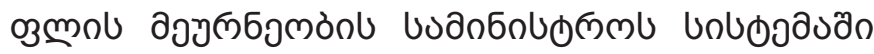

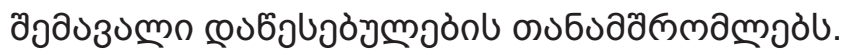

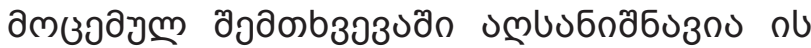

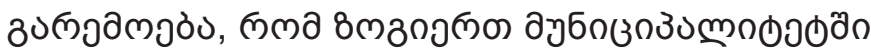

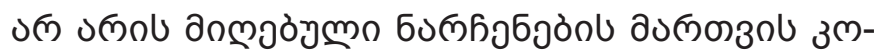

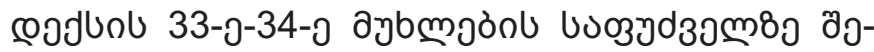

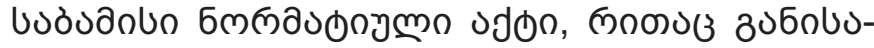

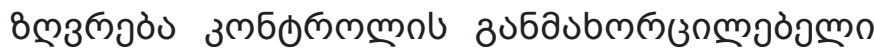

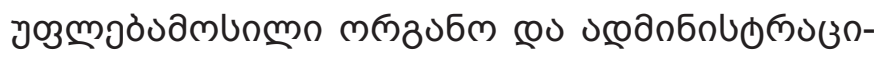

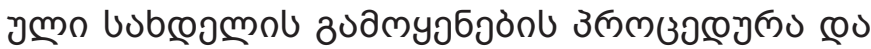

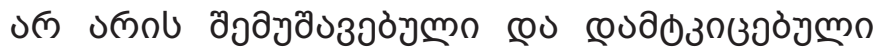

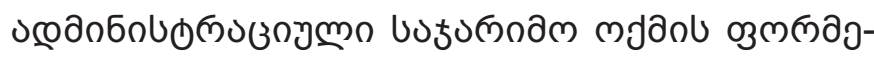

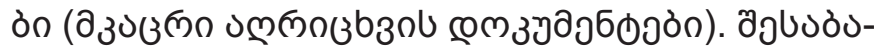

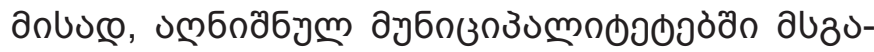

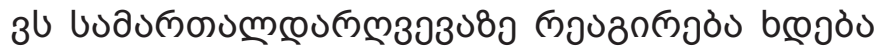

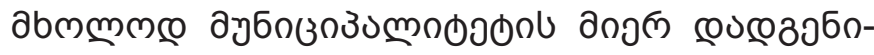

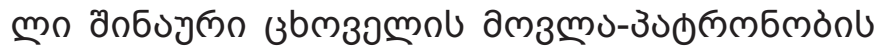

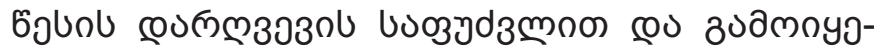

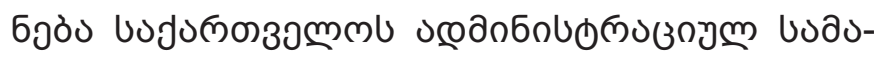

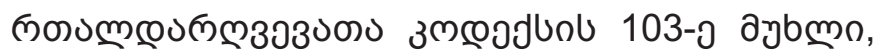

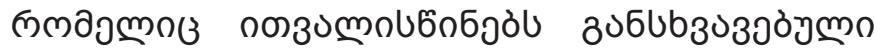
м⿻ু

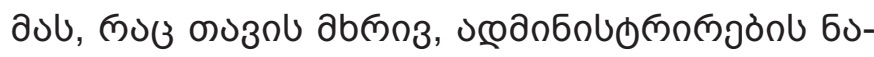

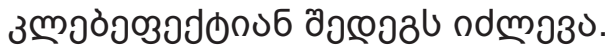

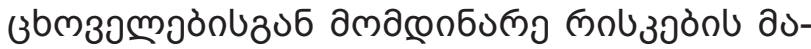

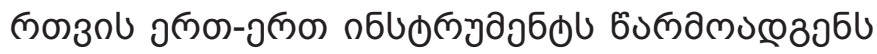

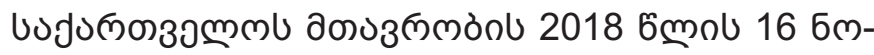

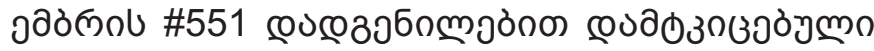

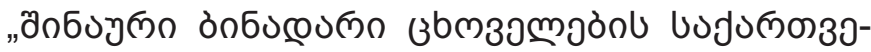

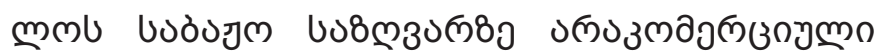

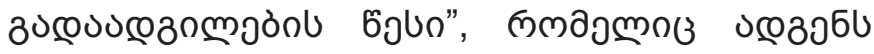

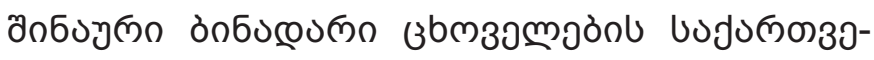

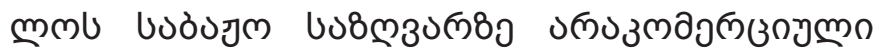

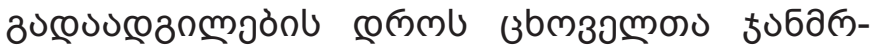

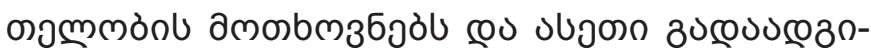

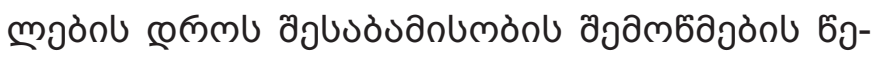

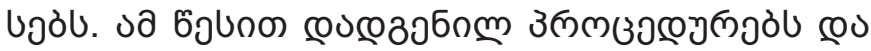

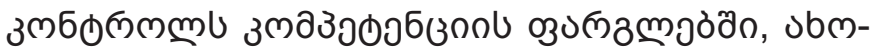

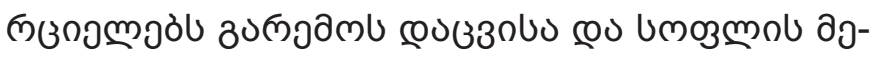

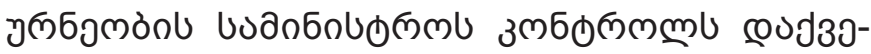

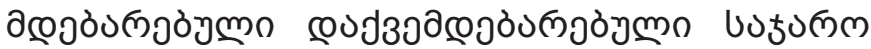

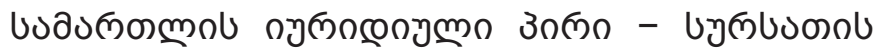

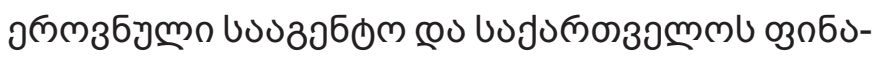

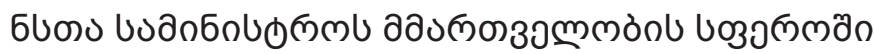

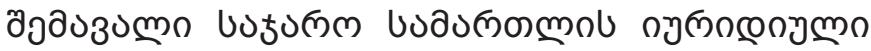

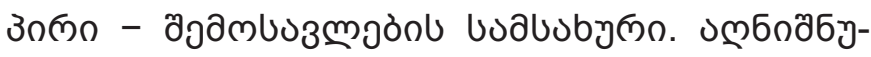

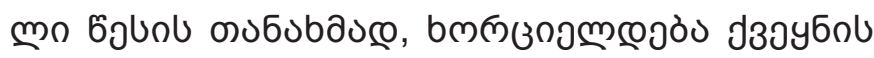

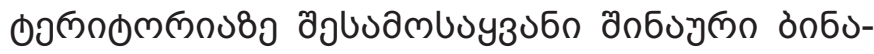

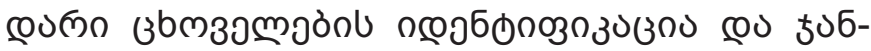

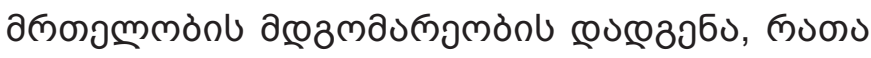

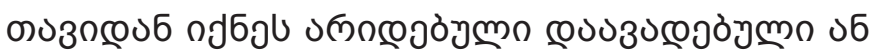

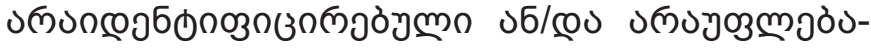

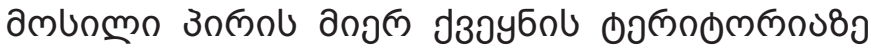

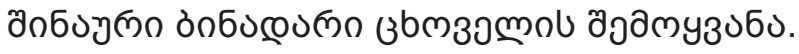

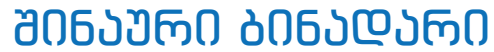

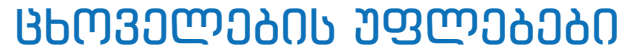

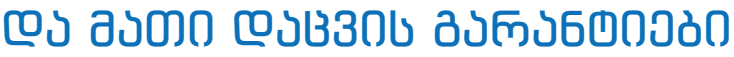

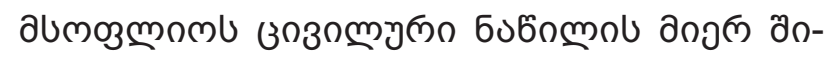

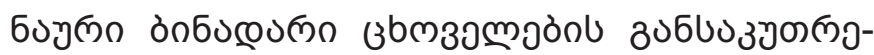

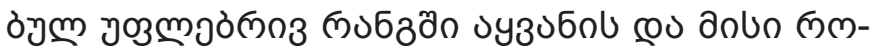

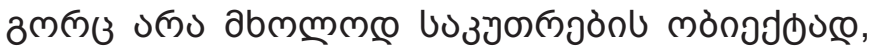

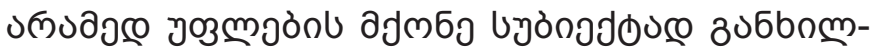

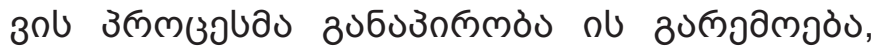

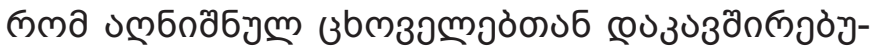

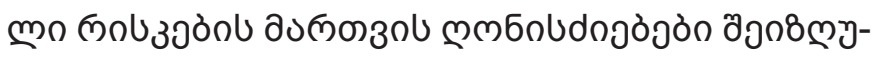

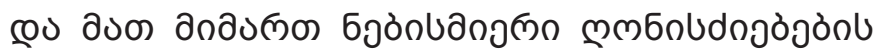

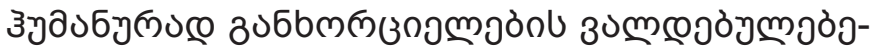

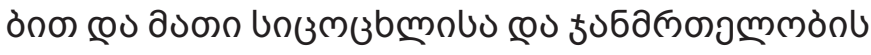

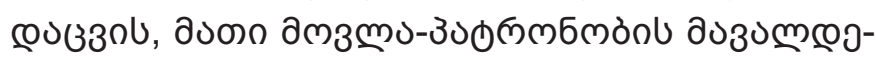

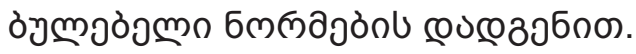

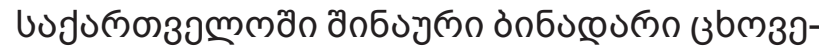

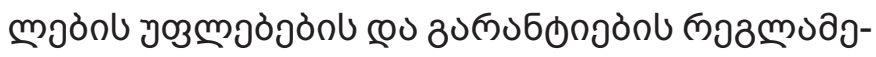

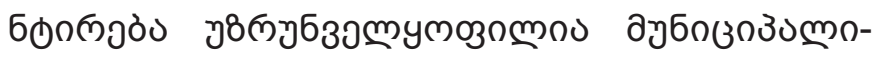

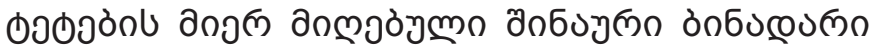

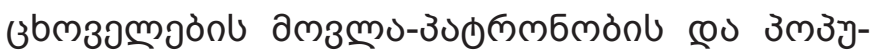

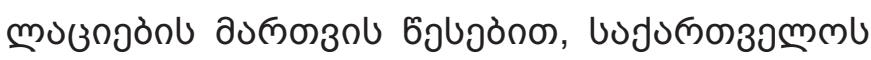

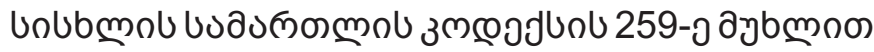




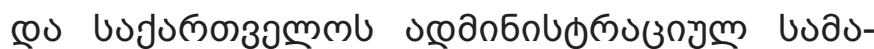

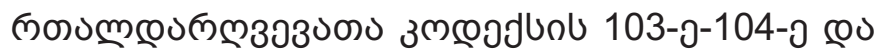

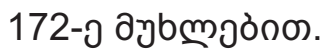

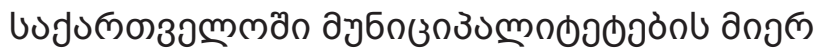

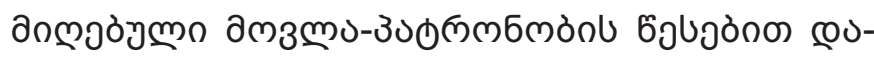

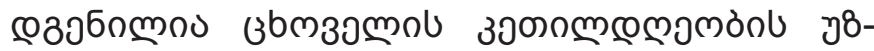

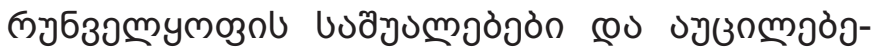

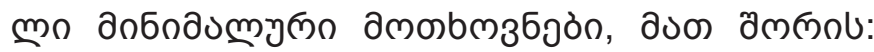

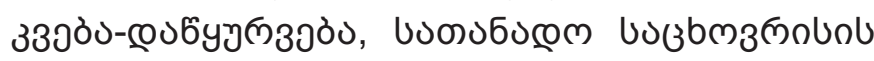

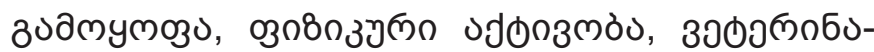

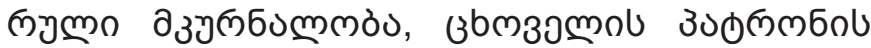

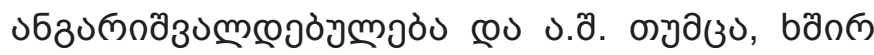

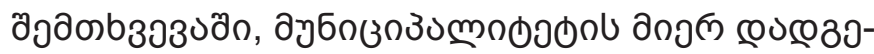

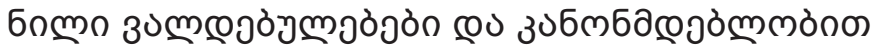

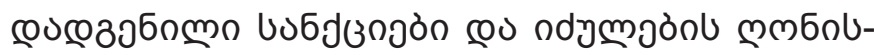

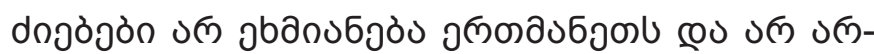

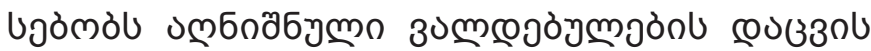

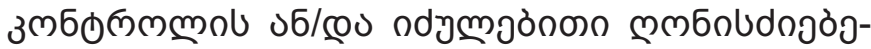

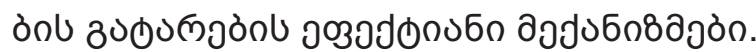

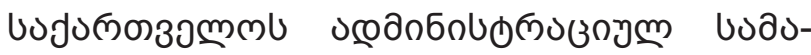

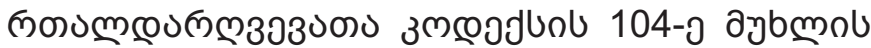

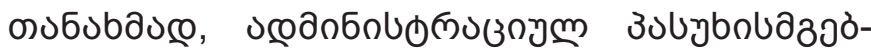

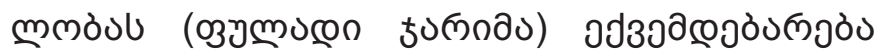

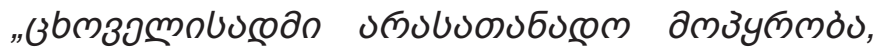

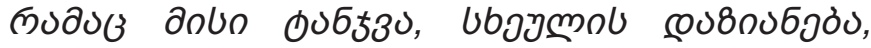

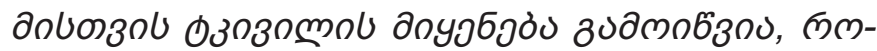

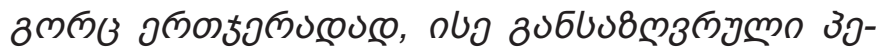

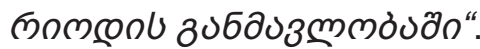

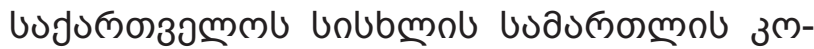

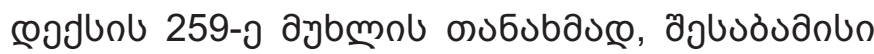

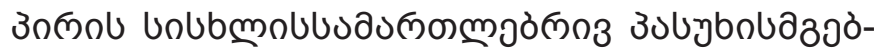

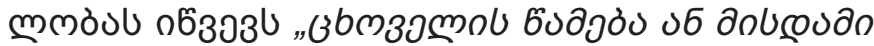

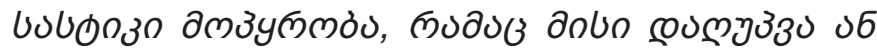

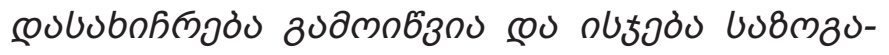

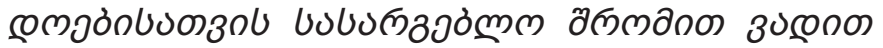

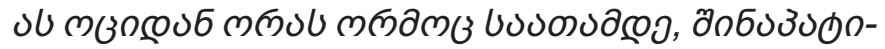

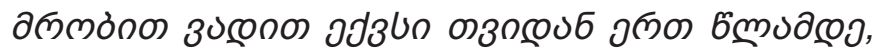

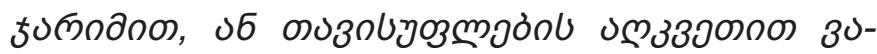

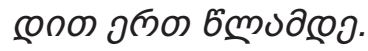

овозо уалгојо, Блголбомо:

ง) 587037 пого

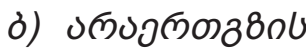

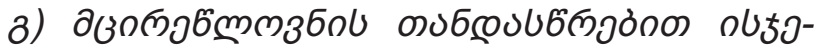

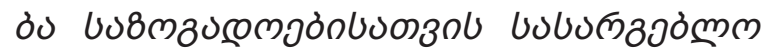

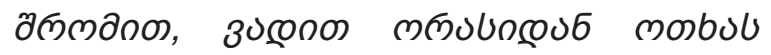

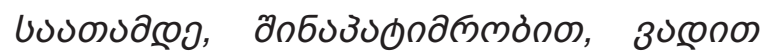

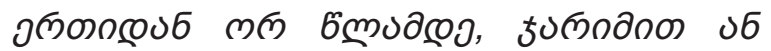

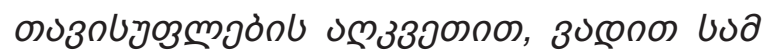

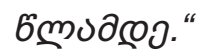

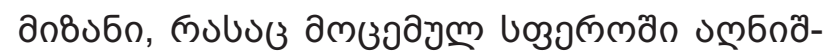

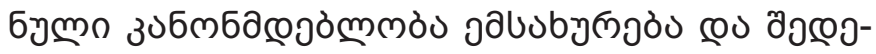

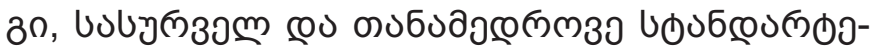

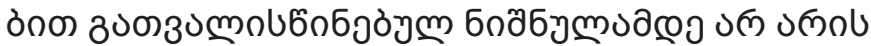

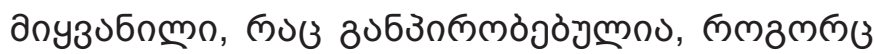

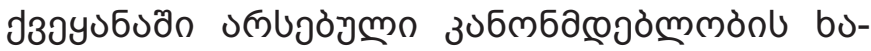

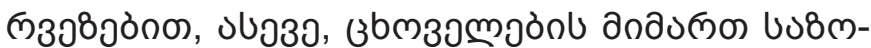

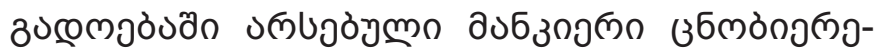

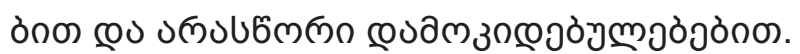

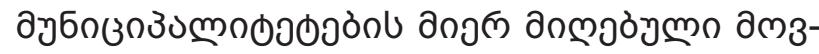

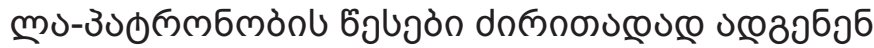

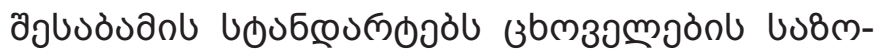

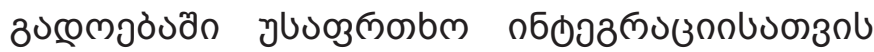

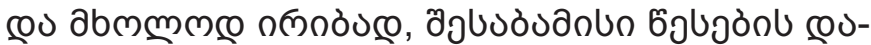

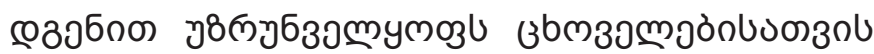

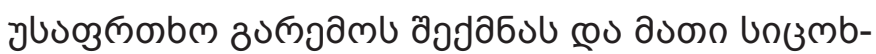

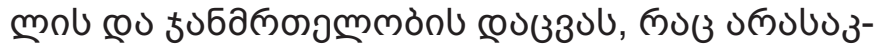

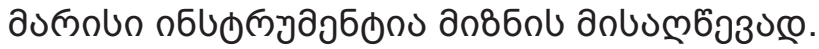

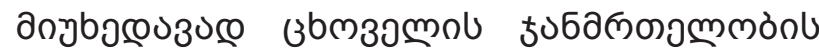

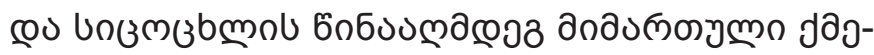

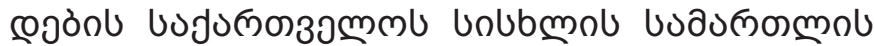

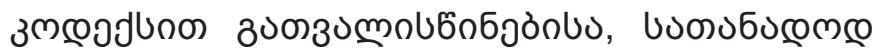

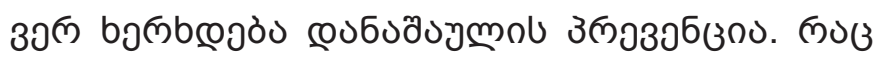

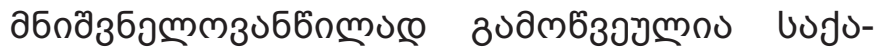

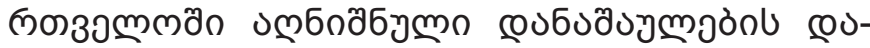

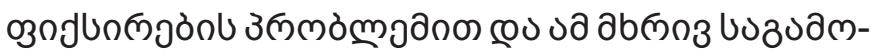

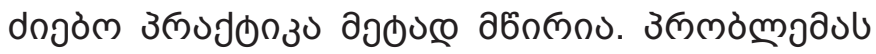

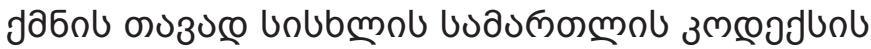

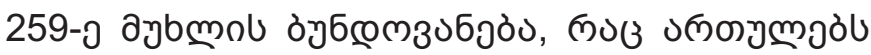

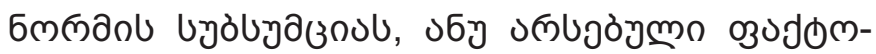

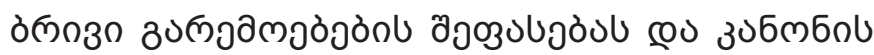

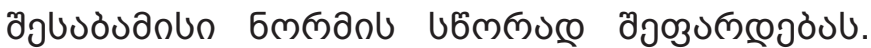

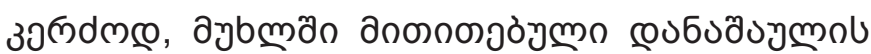

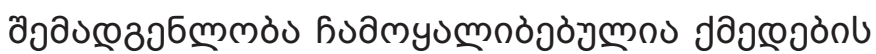

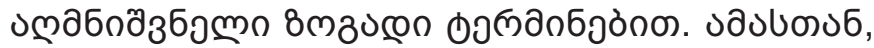

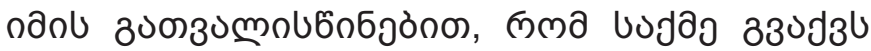

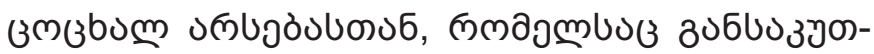

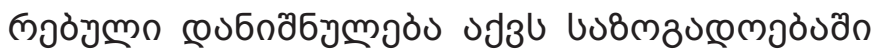

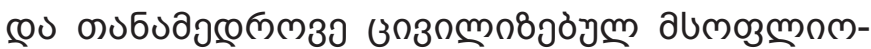

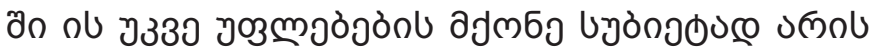

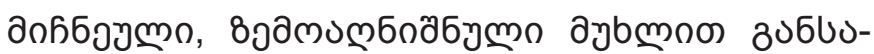

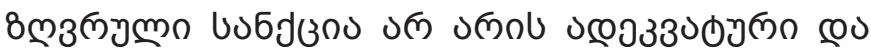
an

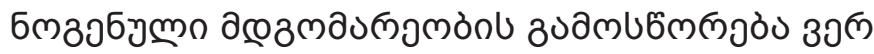

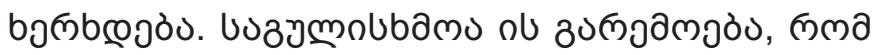

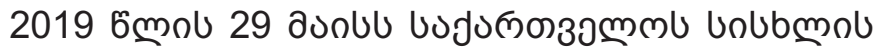

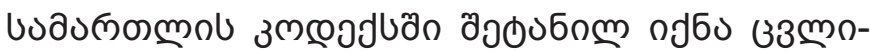

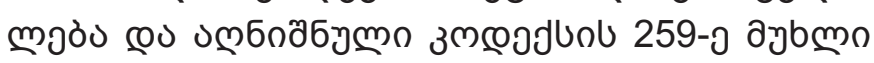

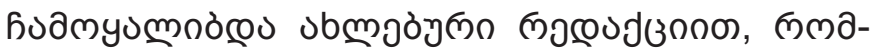




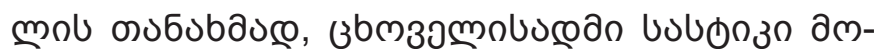

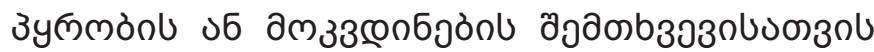

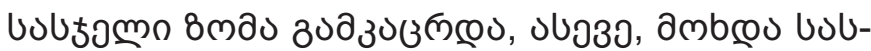

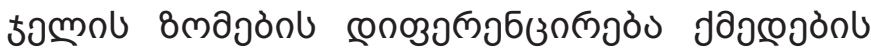

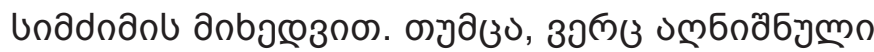

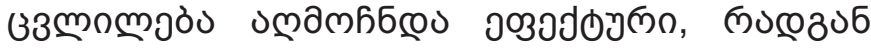

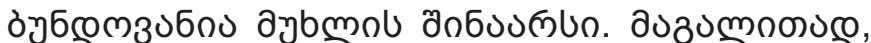

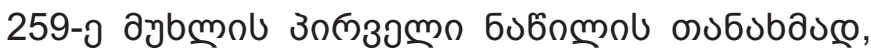

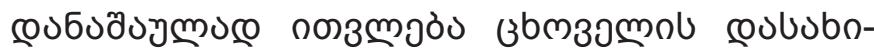

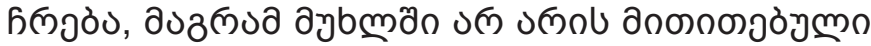

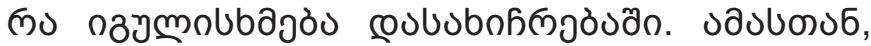

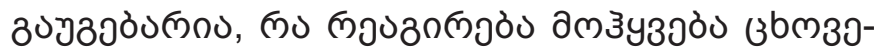

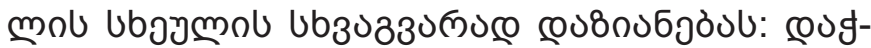

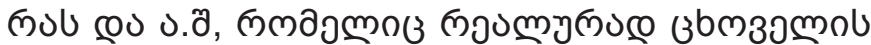

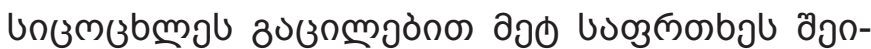

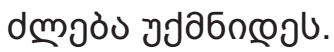

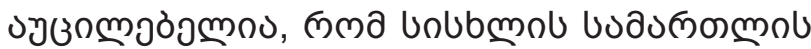

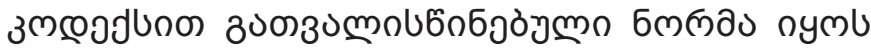

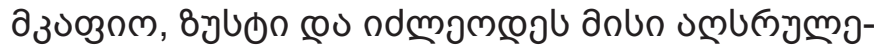

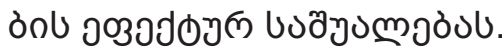

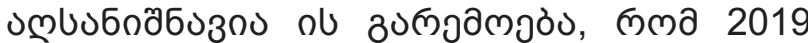
6mol 29 aunbl, unbbmol usasmmmol зм-

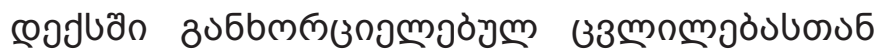

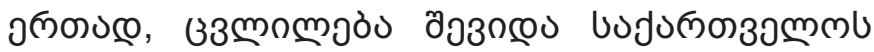

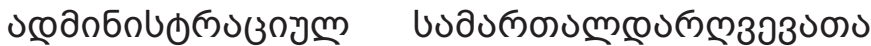

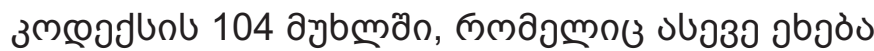

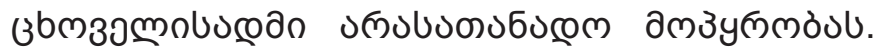

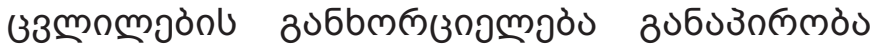

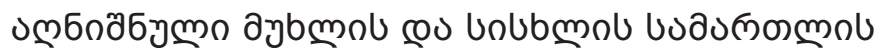

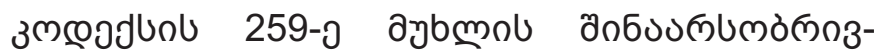

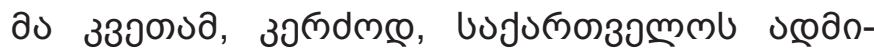

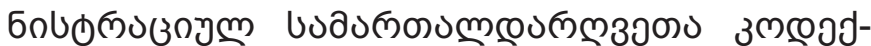

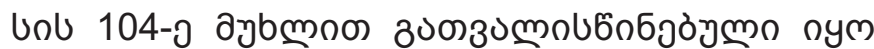

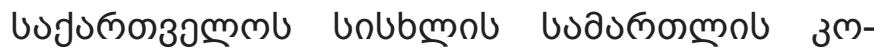

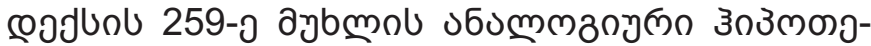

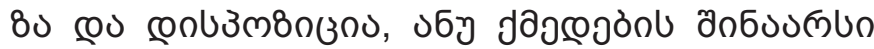

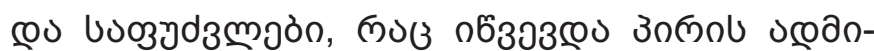

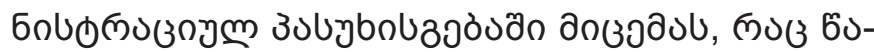

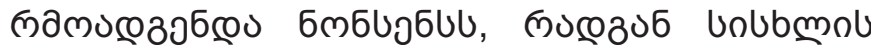

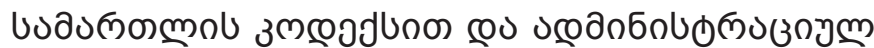

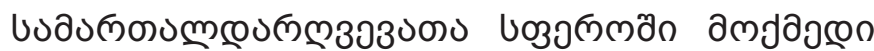

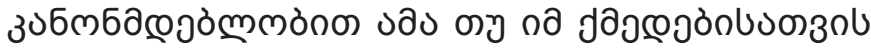

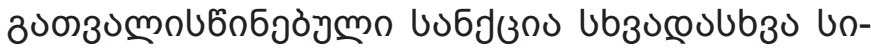

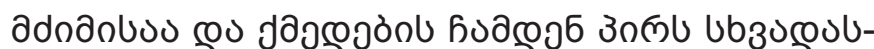

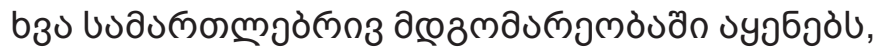

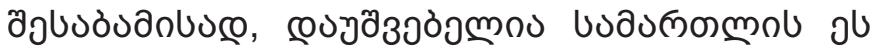

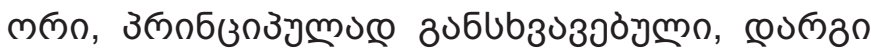

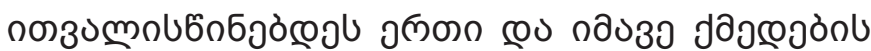

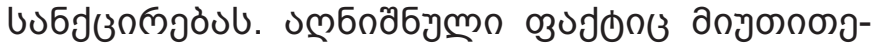

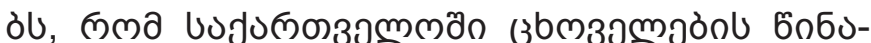

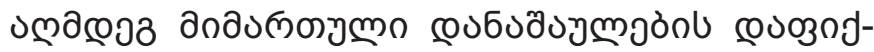

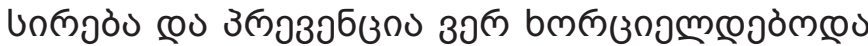

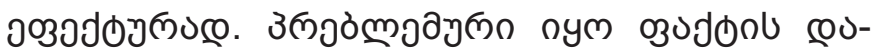

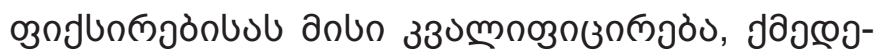

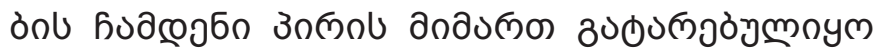

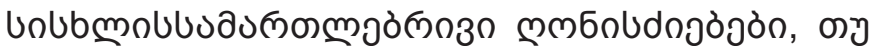

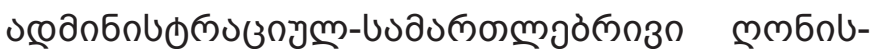

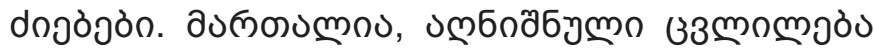

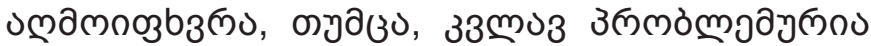
unbbmol usaummmol зmкоJun 259-0 ay-

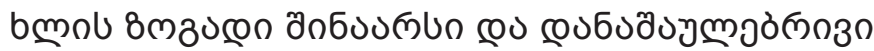

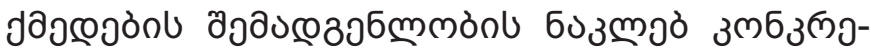

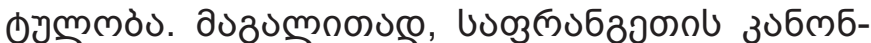

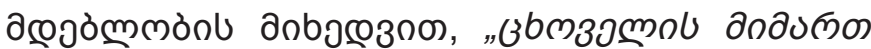

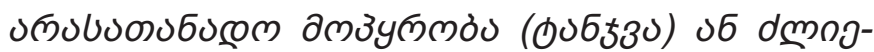

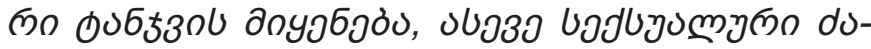

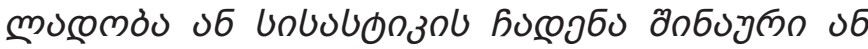

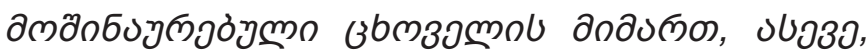

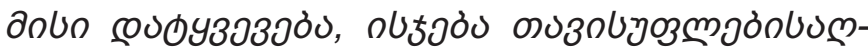

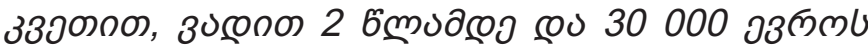

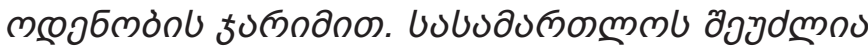

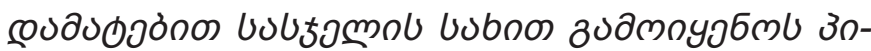

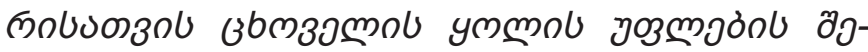

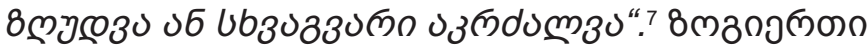

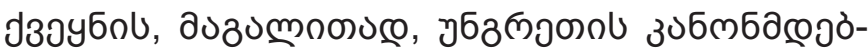

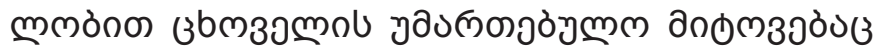

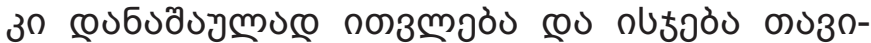

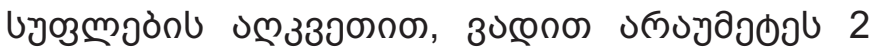

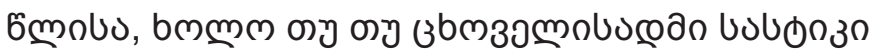

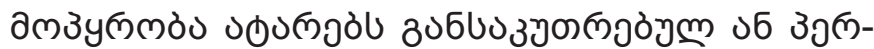

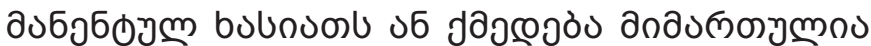

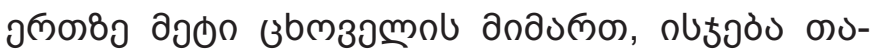

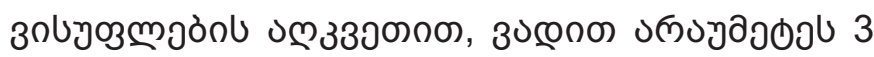

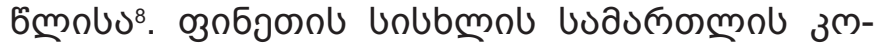

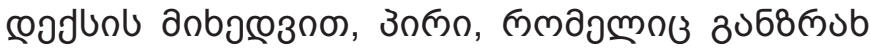

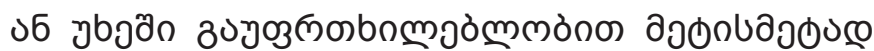

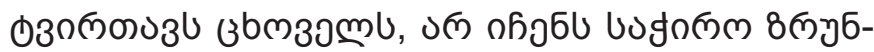

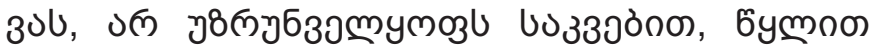

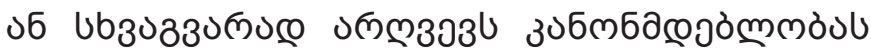

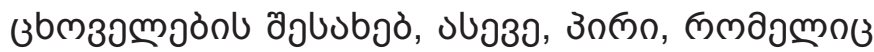

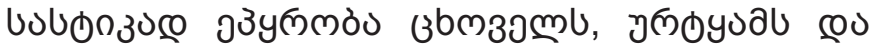

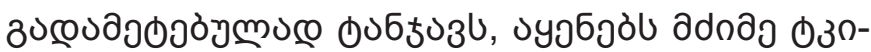

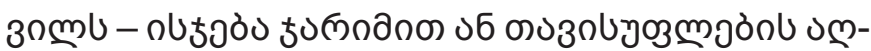

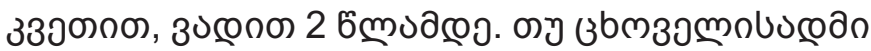

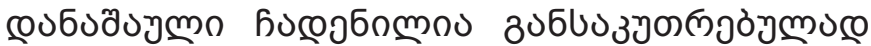

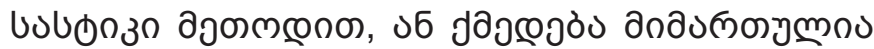

\footnotetext{
7 French Penal Code, Article 521-1.

8 Hungarian Act on the Criminal Code Section 266/B.
} 


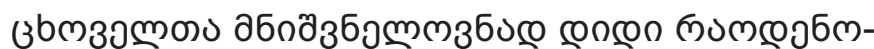

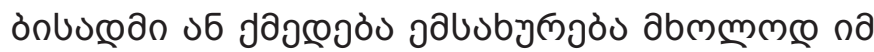

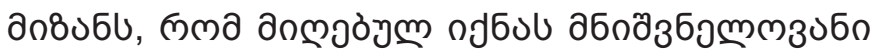

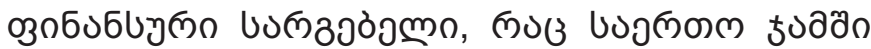

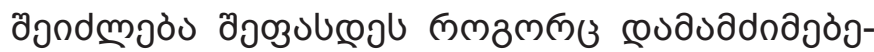

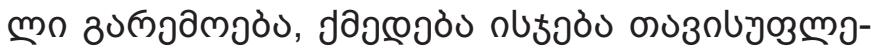

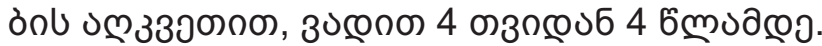

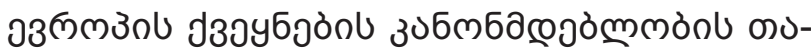

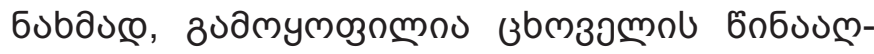

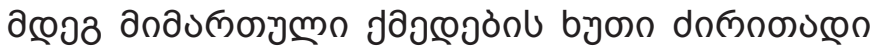
usbo:

1. зимзомо дмззмл

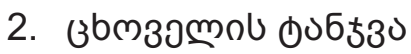

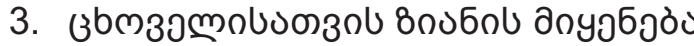

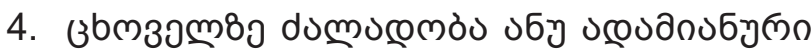

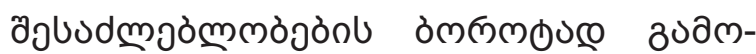
yอбอวิง.

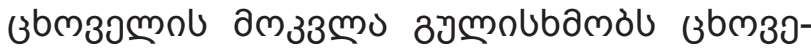

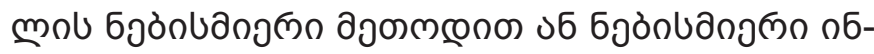

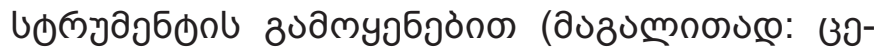

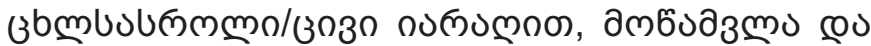

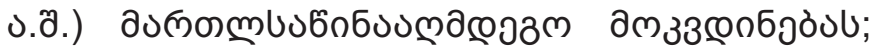

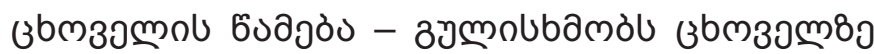

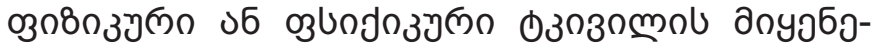

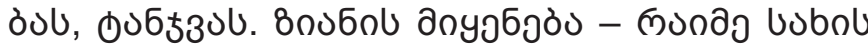

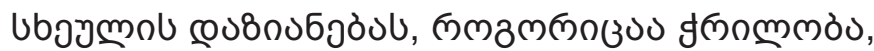

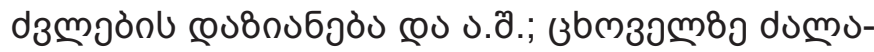

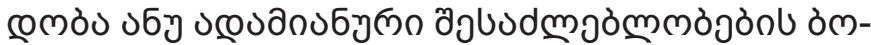

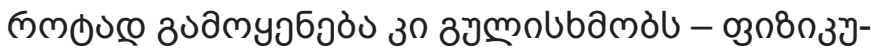

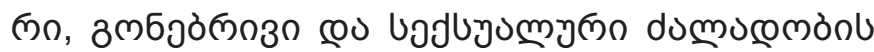

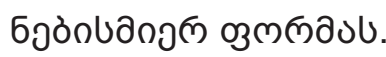

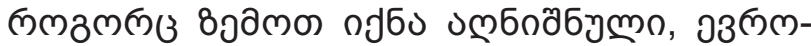

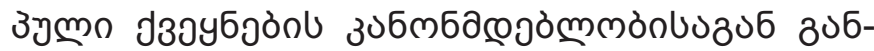

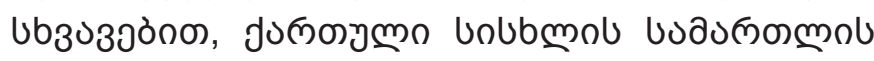

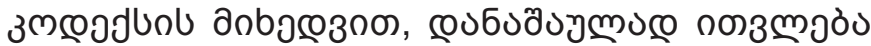

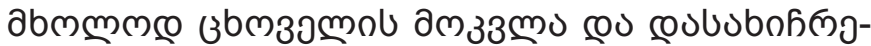

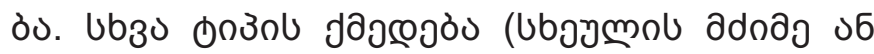

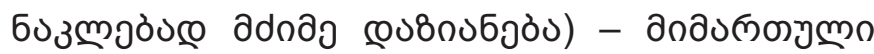

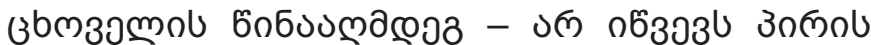

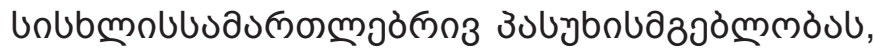

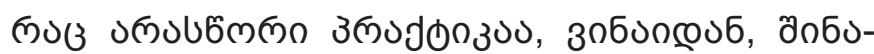

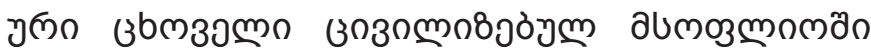

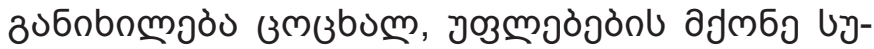

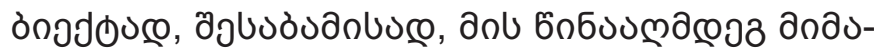

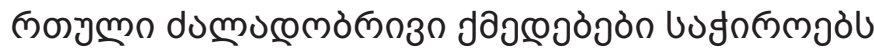

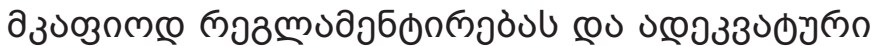

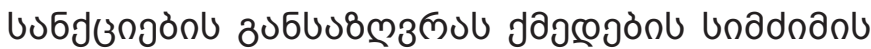

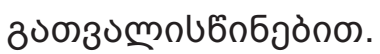

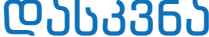

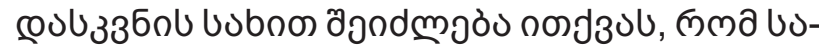

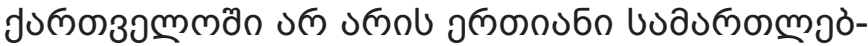

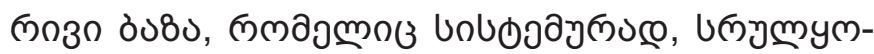

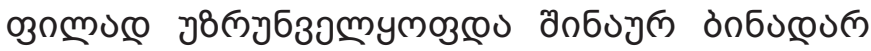

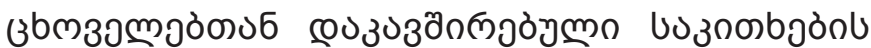

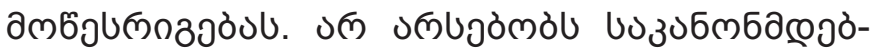

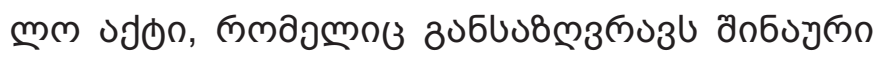

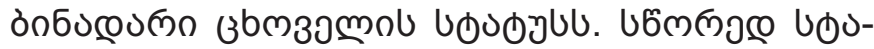

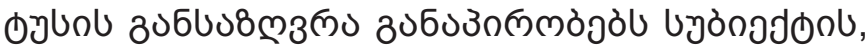

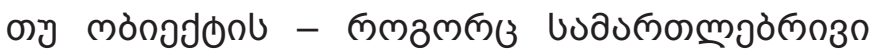

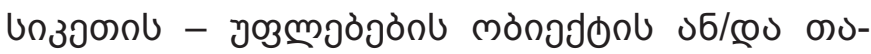

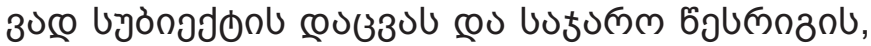

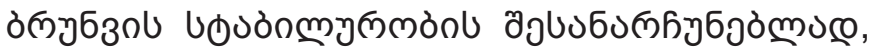

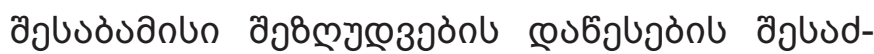
mó̀mmóul.

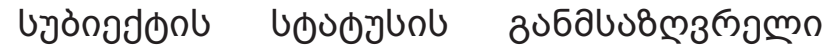

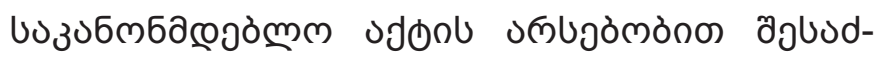

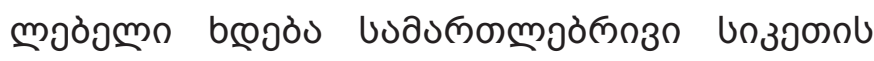

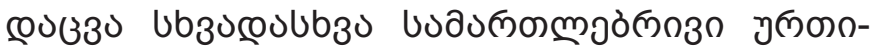

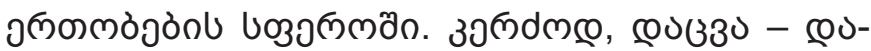

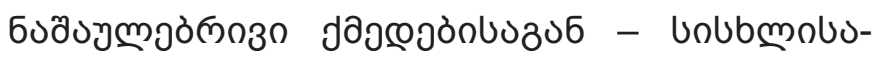

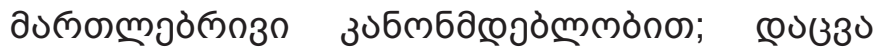

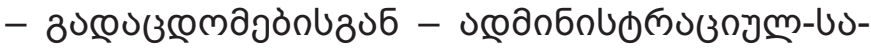

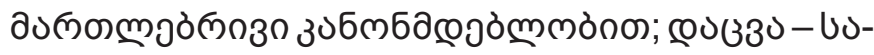

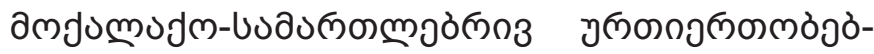

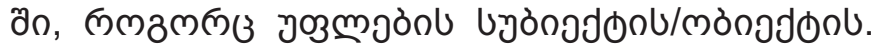

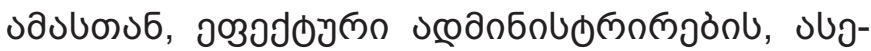

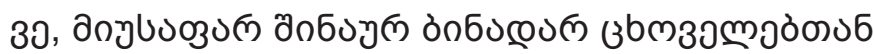

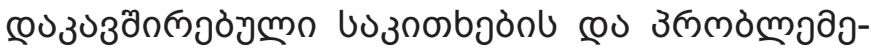

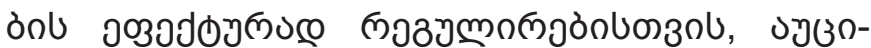

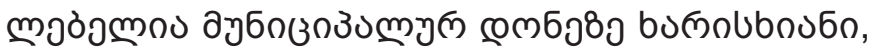

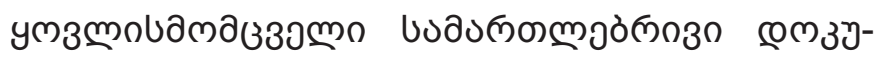

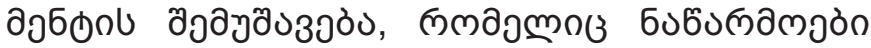

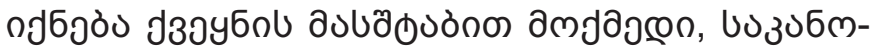

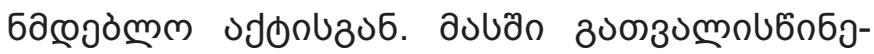

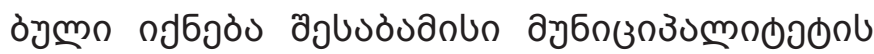

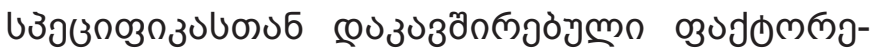

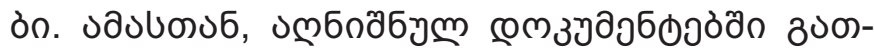

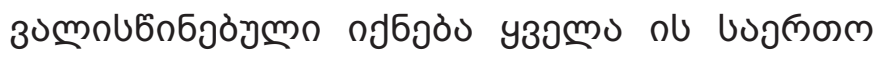

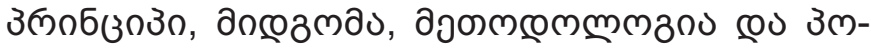

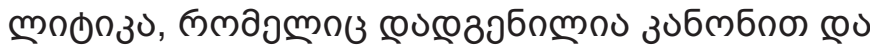

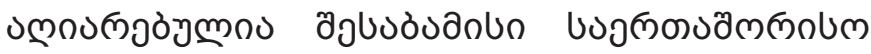

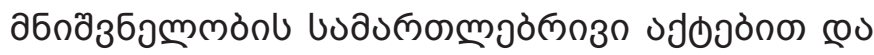

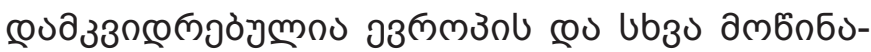

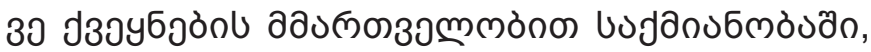

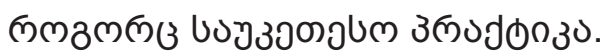

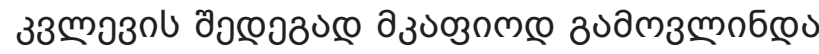




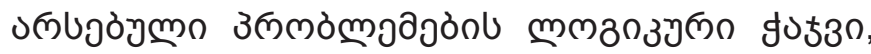

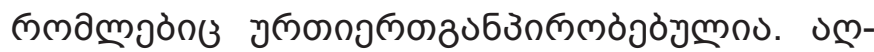

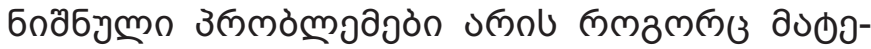

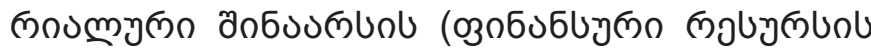

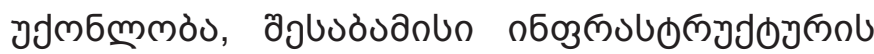

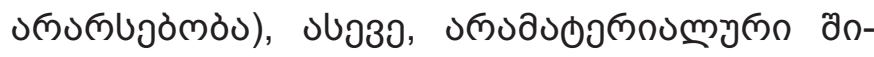

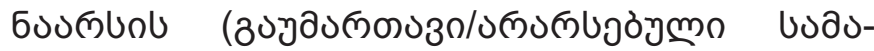

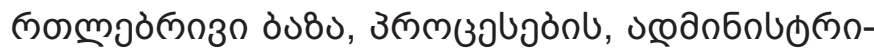

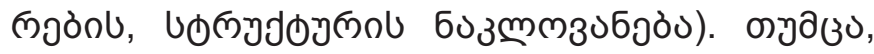

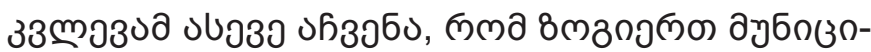

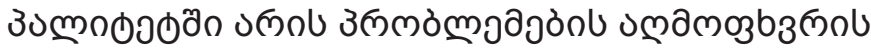

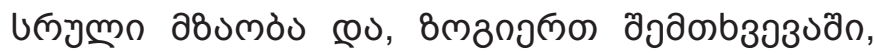

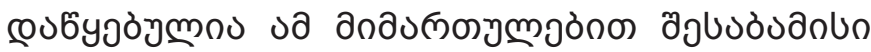

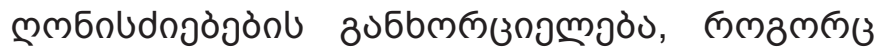

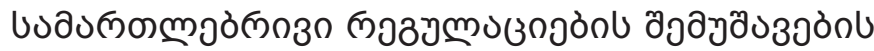

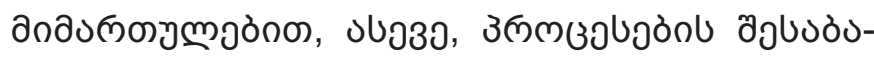

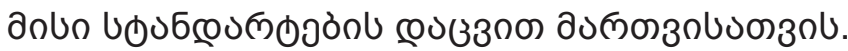

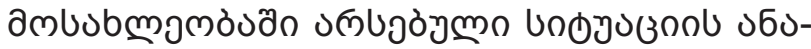

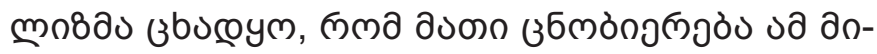

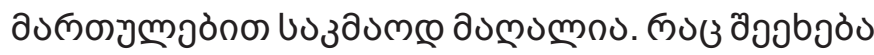

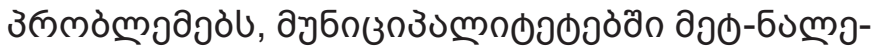

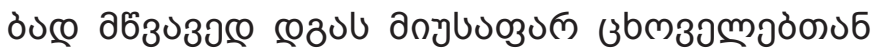

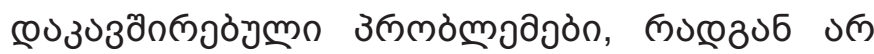

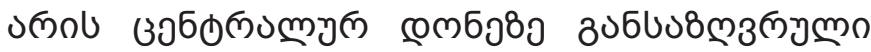

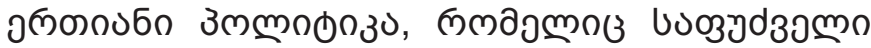

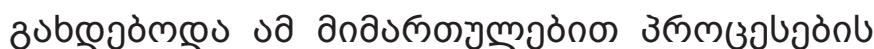

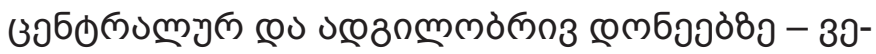

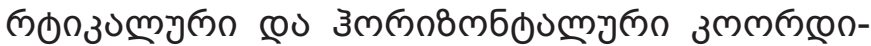

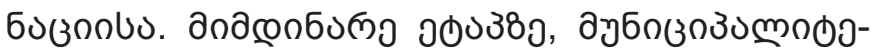

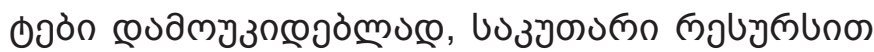

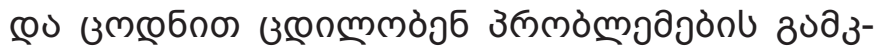

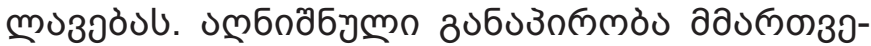

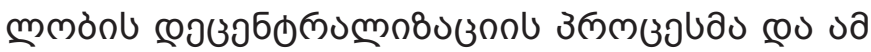

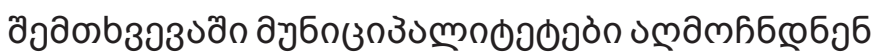

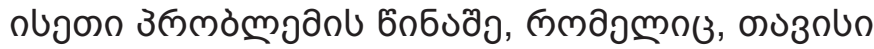

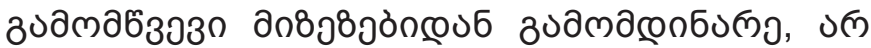

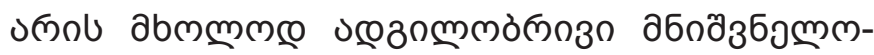

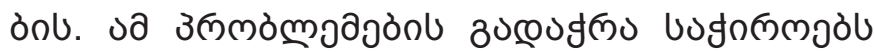

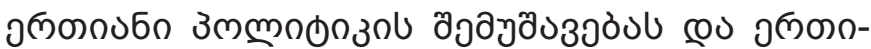

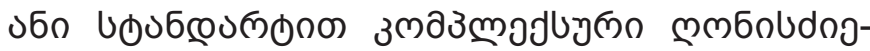

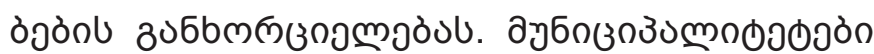

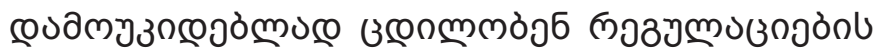

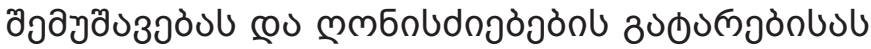

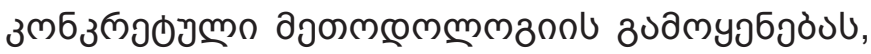

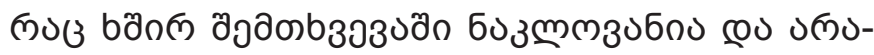

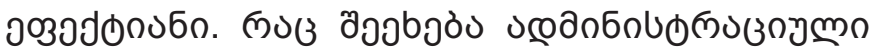

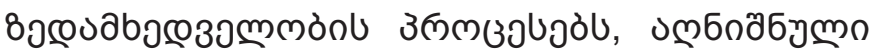

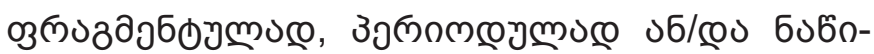

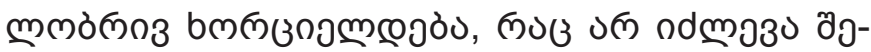

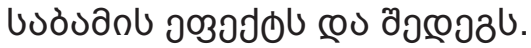

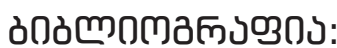

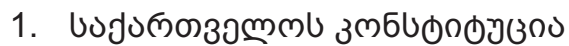

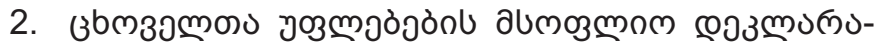
300

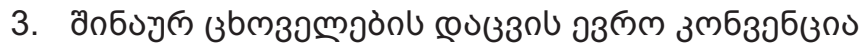

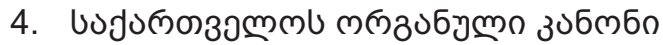

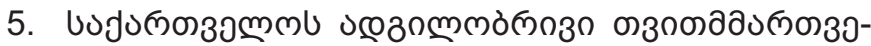

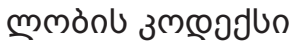

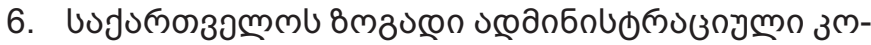
coojun

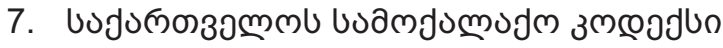

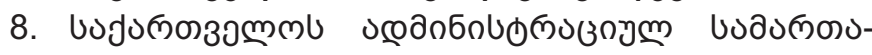

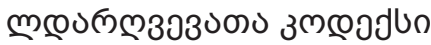

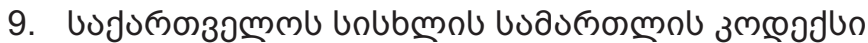

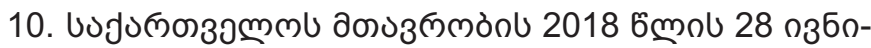

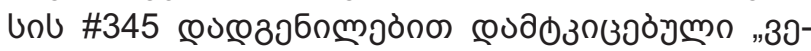

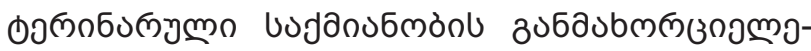

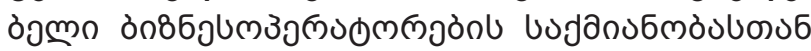

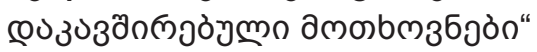

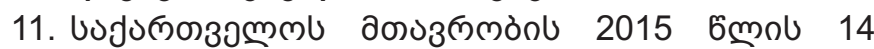

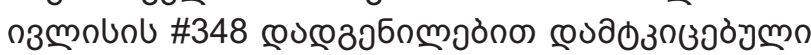

\section{BIBLIOGRAPHY:}

1. The Constitution of Georgia

2. The World Declaration on Animal Rights

3. The European Convention for the Protection of Pet Animals

4. The Organic Law of Georgia

5. The Code of Local Self-Government of Georgia

6. The General Administrative Code of Georgia

7. The Civil Code of Georgia

8. The Administrative Offenses Code of Georgia

9. The Criminal Code of Georgia

10. The Requirements related to the activities of business operators performing veterinary activities approved by Resolution \#345 of the Government of Georgia of June 28, 2018

11. The Rules for implementation of preventive and quarantine measures against animal transferrable diseases approved by Resolution \#348 of the Government of Georgia of July 14, 2015

12. The Rule of non-commercial movement of pet animals across the customs border of Georgia approved 


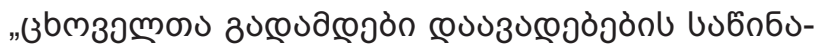

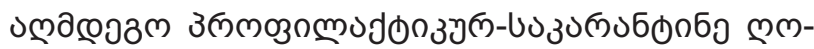

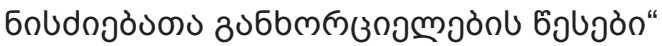

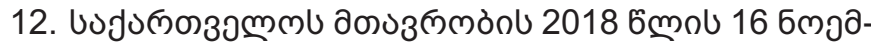

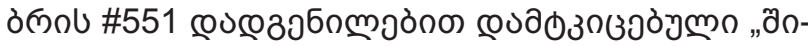

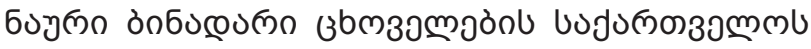

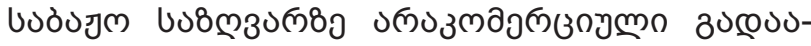
coznmodou 6วun"

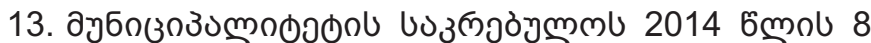

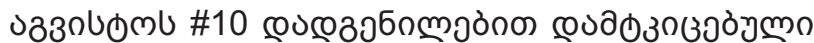

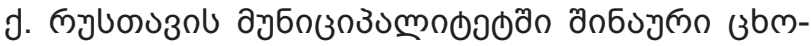

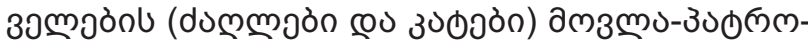

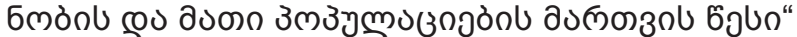

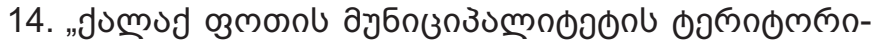

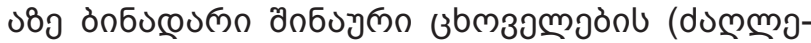

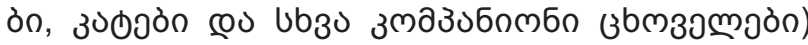

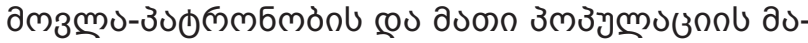

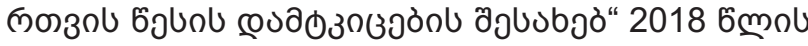

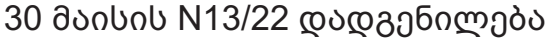

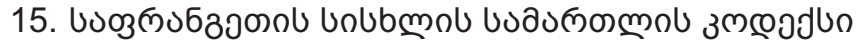

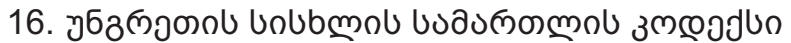

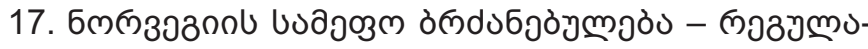

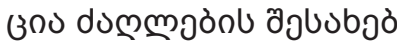

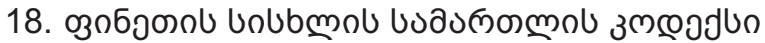

by Resolution \#551 of the Government of Georgia of November 16, 2018

13. The Rules for caring pets (dogs and cats) and controlling their populations in Rustavi Municipality, approved by Resolution \#10 of the Municipality Council of August 8, 2014

14. Resolution N13/22 of May 30, 2018 on the approval of the Rules for caring pets (dogs, cats and other companion animals) and controlling their population on the territory of Poti Municipality

15. The Criminal Code of France

16. The Criminal Code of Hungary

17. The Royal Decree of Norway - the Regulation on Dogs

18. The Criminal Code of Finland

NOTES:

1. Regulations on dogs. https://lovdata.no/dokument/SF/forskrift/2004-08-20-1204

2. Constitution of Georgia, Article 4, 5, 18

3. Organic law of Georgia Local self-government code, Article 16, II, "q"

4. Law of Georgia Waste Management Code, Articles 33, 47

5. Georgian Government Regulation N348, Append. N5, Articles 3,4

6. European Convention for the Protection of Pet Animals, Universal Declaration of Animal Rights

7. French Penal Code, Article 521-1

8. Hungarian Act on the Criminal Code Section 266/B 